\title{
Review \\ Expediting Finite Element Analyses for Subject-Specific Studies of Knee Osteoarthritis: A Literature Review
}

\author{
Alexander Paz ${ }^{1,2, *}$, Gustavo A. Orozco ${ }^{1,3}$, Rami K. Korhonen ${ }^{1}$, José J. García ${ }^{2}$ and Mika E. Mononen ${ }^{1}$ \\ 1 Department of Applied Physics, University of Eastern Finland, 70211 Kuopio, Finland; \\ gustavo.orozco@bme.lth.se (G.A.O.); rami.korhonen@uef.fi (R.K.K.); mika.mononen@uef.fi (M.E.M.) \\ 2 Escuela de Ingeniería Civil y Geomática, Universidad del Valle, Cali 76001, Colombia; \\ jose.garcia@correounivalle.edu.co \\ 3 Department of Biomedical Engineering, Lund University, P.O. Box 188, 22100 Lund, Sweden \\ * Correspondence: alexander.paz@uef.fi
}

Citation: Paz, A.; Orozco, G.A.; Korhonen, R.K.; García, J.J.; Mononen, M.E. Expediting Finite Element Analyses for Subject-Specific Studies of Knee Osteoarthritis: A Literature Review. Appl. Sci. 2021, 11, 11440. https://doi.org/10.3390/ app112311440

Academic Editor: Zimi Sawacha

Received: 13 October 2021

Accepted: 24 November 2021

Published: 2 December 2021

Publisher's Note: MDPI stays neutral with regard to jurisdictional claims in published maps and institutional affiliations.

Copyright: (c) 2021 by the authors. Licensee MDPI, Basel, Switzerland. This article is an open access article distributed under the terms and conditions of the Creative Commons Attribution (CC BY) license (https:// creativecommons.org/licenses/by/ $4.0 /)$.

\begin{abstract}
Osteoarthritis (OA) is a degenerative disease that affects the synovial joints, especially the knee joint, diminishing the ability of patients to perform daily physical activities. Unfortunately, there is no cure for this nearly irreversible musculoskeletal disorder. Nowadays, many researchers aim for in silico-based methods to simulate personalized risks for the onset and progression of OA and evaluate the effects of different conservative preventative actions. Finite element analysis (FEA) has been considered a promising method to be developed for knee OA management. The FEA pipeline consists of three well-established phases: pre-processing, processing, and post-processing. Currently, these phases are time-consuming, making the FEA workflow cumbersome for the clinical environment. Hence, in this narrative review, we overviewed present-day trends towards clinical methods for subject-specific knee OA studies utilizing FEA. We reviewed studies focused on understanding mechanisms that initiate knee OA and expediting the FEA workflow applied to the whole-organ level. Based on the current trends we observed, we believe that forthcoming knee FEAs will provide nearly real-time predictions for the personalized risk of developing knee OA. These analyses will integrate subject-specific geometries, loading conditions, and estimations of local tissue mechanical properties. This will be achieved by combining state-of-the-art FEA workflows with automated approaches aided by machine learning techniques.
\end{abstract}

Keywords: osteoarthritis; knee joint; articular cartilage; finite element analysis

\section{Introduction}

The knee is a synovial joint that transmits loads and motions between the distal femur and proximal tibia bones, mediated by the lever function of the patella. It allows joint rotations (internal-external, varus-valgus, and extension-flexion) and relative translations of the contacting bones to each other (in anterior-posterior, medial-lateral, and distalproximal directions). Normal joint function is guaranteed by the smooth interaction of specialized joint tissues within the knee (Figure 1). A thin articular cartilage layer covers the bone ends, ensuring almost frictionless contact between the bones and reducing impact joint loads. Crescent-shaped menisci, located between the femur and tibia at both lateral and medial compartments, reduce the contact pressures in articular cartilage. Ligaments stabilize the knee joint and restrict excessive joint motions during different physical activities, while tendons transmit muscle forces to bony structures [1-4]. All knee joint tissues work in harmony to maintain the health of the joint; however, when functionality in any of the knee components is disturbed, for instance, due to overweightness or trauma, the joint is exposed to the development of osteoarthritis (OA) $[5,6]$. 


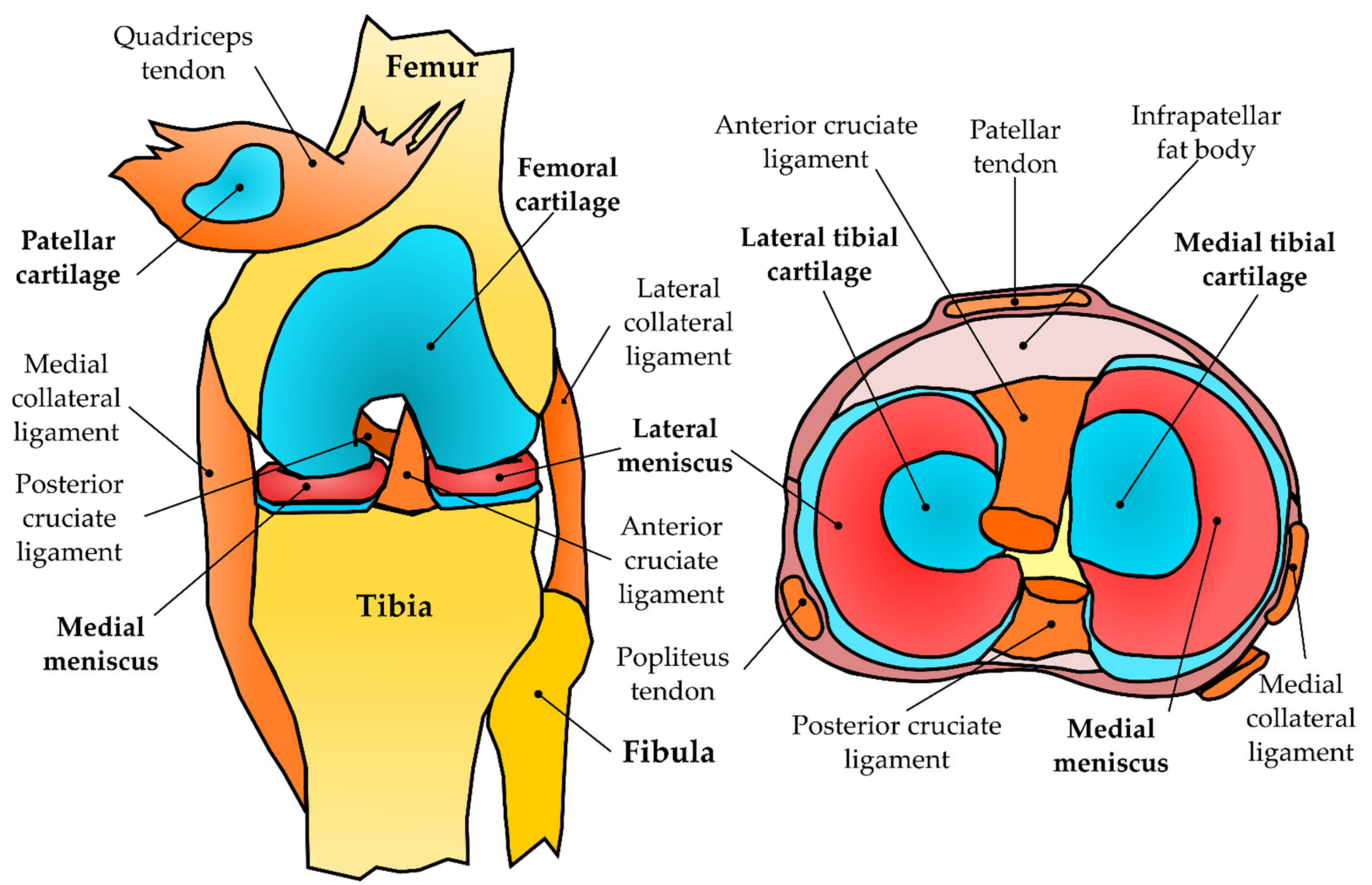

Figure 1. Frontal (left) and coronal (right) views of the internal structures of a left knee joint. Light yellow represents bone structures, orange ligaments and tendons, red menisci, and light blue articular cartilages.

$\mathrm{OA}$ is a degenerative disease that weakens the mechanical properties of articular cartilage and bone [5,7]. Knee OA was responsible for sequelae in more than 250 million people worldwide and caused 14 million years lived with disability (YLDs) globally in 2010 [8]. Symptom treatments and surgical interventions make OA an expensive illness for countries, causing an economic burden of approximately $2 \%$ of GDP $[9,10]$. For instance, it has been estimated that a total knee joint replacement (TKR) surgery may cost up to 50,000 USD, and monitoring the success of the surgery may double those costs [11]. Furthermore, over 600,000 TKR surgeries take place in the US annually [12], exposing the necessity of preventative alternatives to surgery.

The major risk factors for the onset and progression of OA comprise age, gender, genetics, overweightness, joint misalignment, and joint injuries [5,7,13-18]. These risk factors can be modifiable, such as weight and misalignment, or unmodifiable, such as age and genetics. However, due to the patient-specific nature of the disease, predicting its progression is extremely challenging. Therefore, there is an unmet need for clinical tools that would give answers to two questions: (1) Will the current knee joint state and physical activity habits lead to severe OA? (2) If yes, can OA be prevented or its progression delayed by conservative treatments (e.g., weight loss, gait retraining, physical exercise)? Promising computational methods are intended to solve them.

Artificial intelligence- (AI-) based solutions have been developed to predict joint condition using baseline information $[19,20]$. These methods have shown capabilities to classify patients into low-risk and high-risk groups based on subject characteristics. However, they have limitations in simulating the effects of different interventions because they require a large amount of training data to include all possible treatment options. Currently, such data are not available. 
Finite element (FE) analysis (FEA) is another computational approach that solves physics-based problems using constitutive and governing equations. FEA has been, for three decades, a non-invasive strategy to study how different biomechanical risk factors may impact knee joint tissues. It has helped researchers understand cartilage degeneration mechanisms at the tissue level and knee joint biomechanics under various loading conditions in health and disease [21-29].

In general, an FEA is performed in three stages: a pre-processing stage to prepare the model, a processing stage to solve the mathematical problem, and a post-processing stage to analyze the results and draw conclusions. Especially for knee joint FEAs, the time required to generate accurate subject-specific models, with detailed three-dimensional (3D) geometries and feasible FE meshes, is the main drawback for clinical implementation, since it may take several working days per individual [30-33].

At this point, it is valuable to describe the state-of-the-art FEAs for evaluating the onset and progression of knee OA towards future clinical implementations. To this end, this narrative review aimed to present an overview of relevant FEA-based studies focused on broadening the understanding of potential mechanisms behind knee OA development and those focused on expediting the FEA pipeline to simulate three-dimension models of the knee at the whole-organ level. For that, we sourced published scientific papers from ScienceDirect, PubMed, and SpringerLink databases. Papers including terminologies such as "cartilage", "osteoarthritis", "knee", "three-dimension", "finite element", "imaging", "modeling", "model", "simulation", and "automated" were manually sorted following the aim of this review. Subsequently, we referred to these studies according to the order of presented FEA workflow phases. We present studies with a relevant influence on each phase, followed by studies aiming to save time in the respective phase. Finally, we discuss studies focused on predicting the onset and progression of knee $\mathrm{OA}$ and verification and validation of FEAs.

\section{Development of Knee FEA}

FEA was proposed in the mid-20th century for solving complex problems by discretizing a physical domain into small pieces called elements [34]. FEA is currently used in a wide range of sciences, such as biomechanics, for dealing with nonlinearities of tissue mechanical behavior, complex geometries, and multi-physics interactions [35].

For knee tissue biomechanics, initial studies focused on structural characterization and mathematical description utilizing simple loading conditions. Then, due to improvements in equipment, increasing computing capacity, and theoretical enrichment, more realistic geometries and loading conditions were included in the numerical models. Thus, the route from the first 3D knee joint model until now has been a long 40-year journey [36-38].

\section{Knee FEA Workflow}

FEA involves three main phases (Figure 2). In the pre-processing stage, the geometry, mesh, constitutive models, loading, and boundary conditions are defined. In the processing stage, the mathematical equations describing the model are solved numerically. In the post-processing stage, the results are usually extracted from the simulation software and analyzed with appropriate programs for further calculations. Additional tasks mandatory for achieving reliable FEA results include mesh convergence analyses, verifications, and validations against experimental data $[30,39,40]$. 


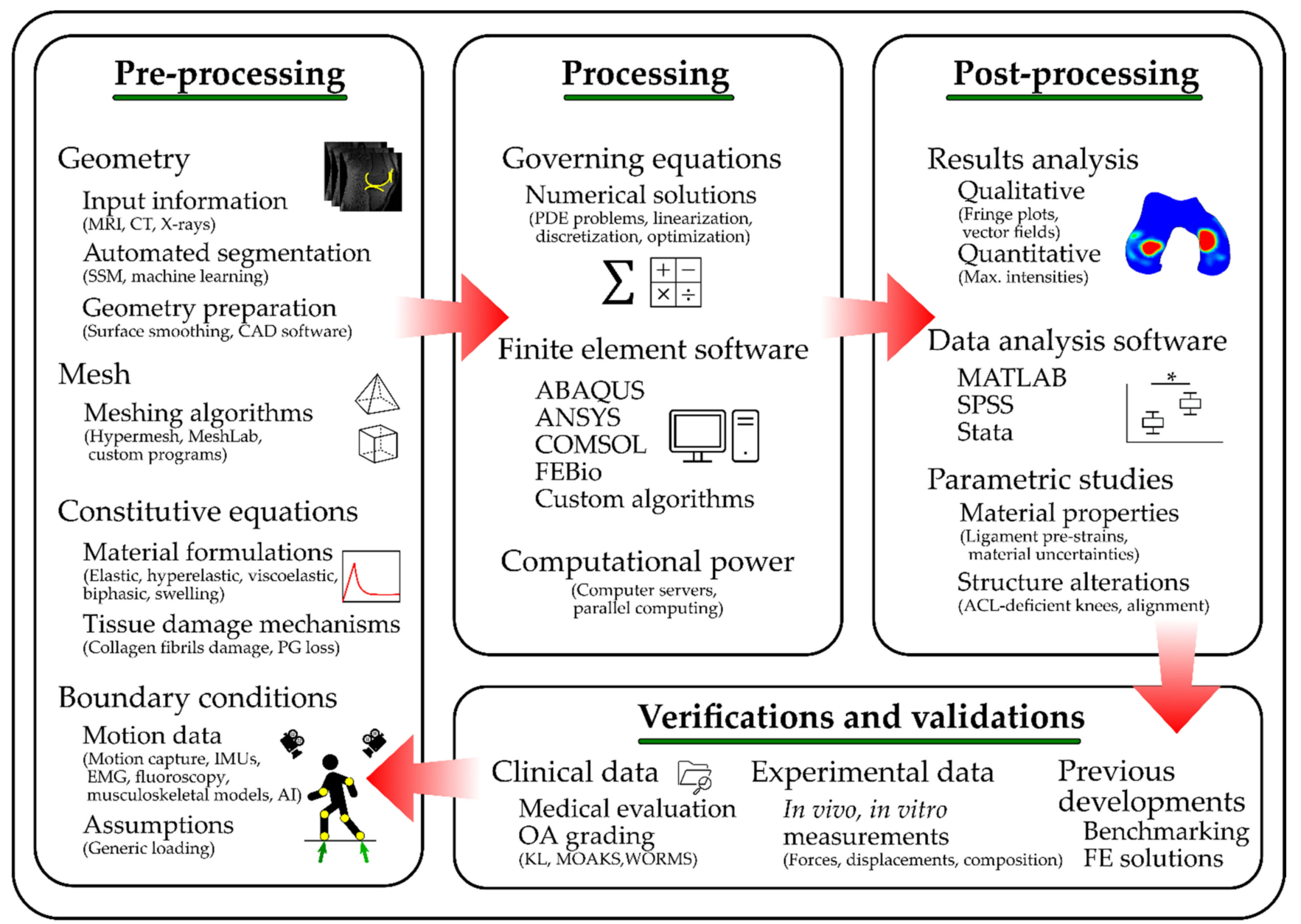

Figure 2. Finite element analysis workflow. Pre-processing integrates preparatory information to define the model. Processing solves the governing equations behind the physical interactions aided by computational tools. Post-processing evaluates the simulation outputs using qualitative and quantitative methods. Verification and validation feeds back into the modeling process to ensure logical results that represent the realistic behavior of the problem in question and draw conclusions regarding the problem simulated. MRI—Magnetic resonance imaging, CT—computed tomography, SSM—statistical shape modeling, CAD—computer aided design, PG—proteoglycan, IMU—inertial measurement unit, EMG—electromyography, AI—artificial intelligence, PDE—partial differential equation, ACL—anterior cruciate ligament, KL-Kellgren-Lawrence score, MOAKS—MRI osteoarthritis knee score, WORMS—whole-organ magnetic resonance imaging score.

\subsection{Pre-Processing}

Knee FEAs face frequent challenges, one of which is to establish the feasible level of detail for a particular study [31,35]. A detailed model requires more information to describe the geometry, constitutive material models, and boundary conditions. Obtaining and implementing this information into a FE model is a time-consuming task. Hence, novel strategies to expedite each of these activities are needed.

\subsubsection{Geometry}

Commonly, an experienced musculoskeletal radiologist segments medical images, identifying and contouring the tissues of interest (bone, cartilage, meniscus, ligaments, and tendons) to obtain their 3D representation. For that, information from magnetic resonance imaging (MRI) or computed tomography (CT) scans can be used. MRI is usually preferred over CT since it has superior soft-tissue contrast and no ionizing radiation is used $[19,41-43]$. 
Manual segmenting of an MRI dataset of the knee, using an $0.5 \mathrm{~mm}$ slice thickness, takes several hours [26,44-46]. For the CT dataset, it takes even longer due to higher image resolution. Hence, the rapid generation of 3D geometries from medical images has received special attention not only for modeling purposes but for surgery planning and implant designing [44-51]. For example, Ambellan et al. [44] automated the segmentation of MRI images via AI. They used convolutional neural networks (CNNs) to rapidly contour tissues in 2D and 3D domains and used statistical shape modeling (SSM) to control zones with high variability in shape, such as those susceptible to osteophytes. The authors trained their custom software with manual segmentations from the MICCAI SKI10 challenge (https:/ / ski10.grand-challenge.org/) (accessed on 13 October 2021) and the Osteoarthritis Initiative (OAI) (https:/ / nda.nih.gov / oai/) (accessed on 13 October 2021). The accuracy of the automated method was as good as that of human experts and reduced the time to one-sixth of a manual procedure. In another example, Paproki et al. [52] sped up the segmentation and analysis of menisci in healthy and osteoarthritic knees from the OAI database. They automated the segmentation process based on active shape modeling (ASM) and SSM. Comparisons revealed that the automated process identified variables useful for OA evaluations such as volume, tibial coverage, and menisci subluxation as well as manual methods did. In total, segmenting and assessing one patient took $\sim 30 \mathrm{~min}$, suggesting the use of this approach for large cohort studies.

Once the geometry is ready, commonly in a shell stereolithography CAD format (.stl), researchers assign a volume to it, translating the shell geometry to a solid format (e.g., .igs). This activity is done by using custom algorithms or CAD software including SolidWorks (SolidWorks Corporation, Waltham, MA, USA), CATIA (Dassault Systèmes, Vélizy-Villacoublay, France), and Rhinoceros (Robert McNeel \& Associates, Seattle, WA, USA).

\subsubsection{Mesh}

As a second step, shell or volumetric geometries of the knee structure are discretized for FEA. This representation of objects as a set of connected elements is the basis of this method [34]. Hence, the accuracy of the numerical results highly depends on the mesh quality.

In FEA, a particular element type may be more appropriate for a problem according to the objective of the study $[53,54]$. The linear tetrahedral is the simplest volumetric element and is preferred for automated meshing methods (Figure 3) $[33,53,55,56]$. However, it overestimates the stiffness at large deformations and numerous elements are needed to ensure solution convergence [35]. In contrast, hexahedral elements are recommended when the problem exhibits a high nonlinear behavior, such as in contact problems [33]. However, it is a challenging task to mesh intricate geometries with only hexahedral elements [57]. Figure 4 shows an example of a knee joint meshed with hexahedral elements from the OpenKnee project [58], freely available at https://simtk.org/projects/openknee (accessed on 13 October 2021). High-order elements (e.g., tet10, tet15, hex20; Figure 3) are recommended to better track deformations and stresses in soft tissues such as cartilage, muscle, or ligament since they produce smoother strain and stress estimates with fewer elements compared to linear approximations (e.g., tet4). In addition, they provide a closer representation of complex curved surfaces [54,57]. 


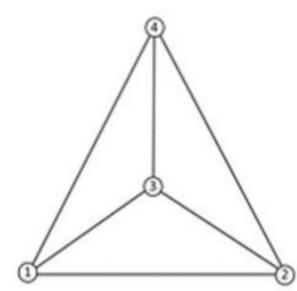

tet4

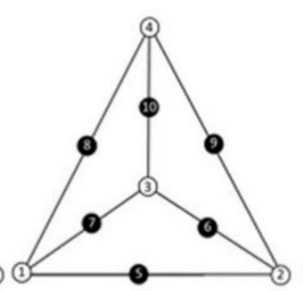

tet10

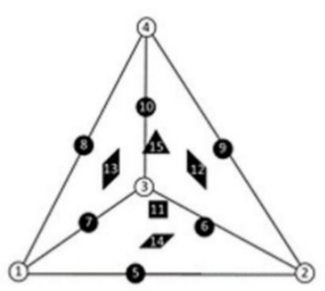

tet15

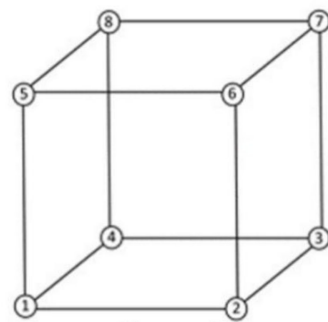

hex8

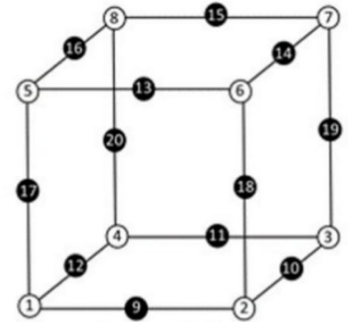

hex20

Figure 3. Some types of solid elements used for FEA. From left to right, tetrahedral of four nodes (tet4), tetrahedral of ten nodes (tet10), tetrahedral of fifteen nodes (tet15), hexahedral of eight nodes (hex8), hexahedral of twenty nodes (hex20). (FEBio User Manual 2.9-3.8.2.1 https:/ / help.febio.org/FEBio/FEBio_um_2_9/index.html) (accessed on 13 October 2021).

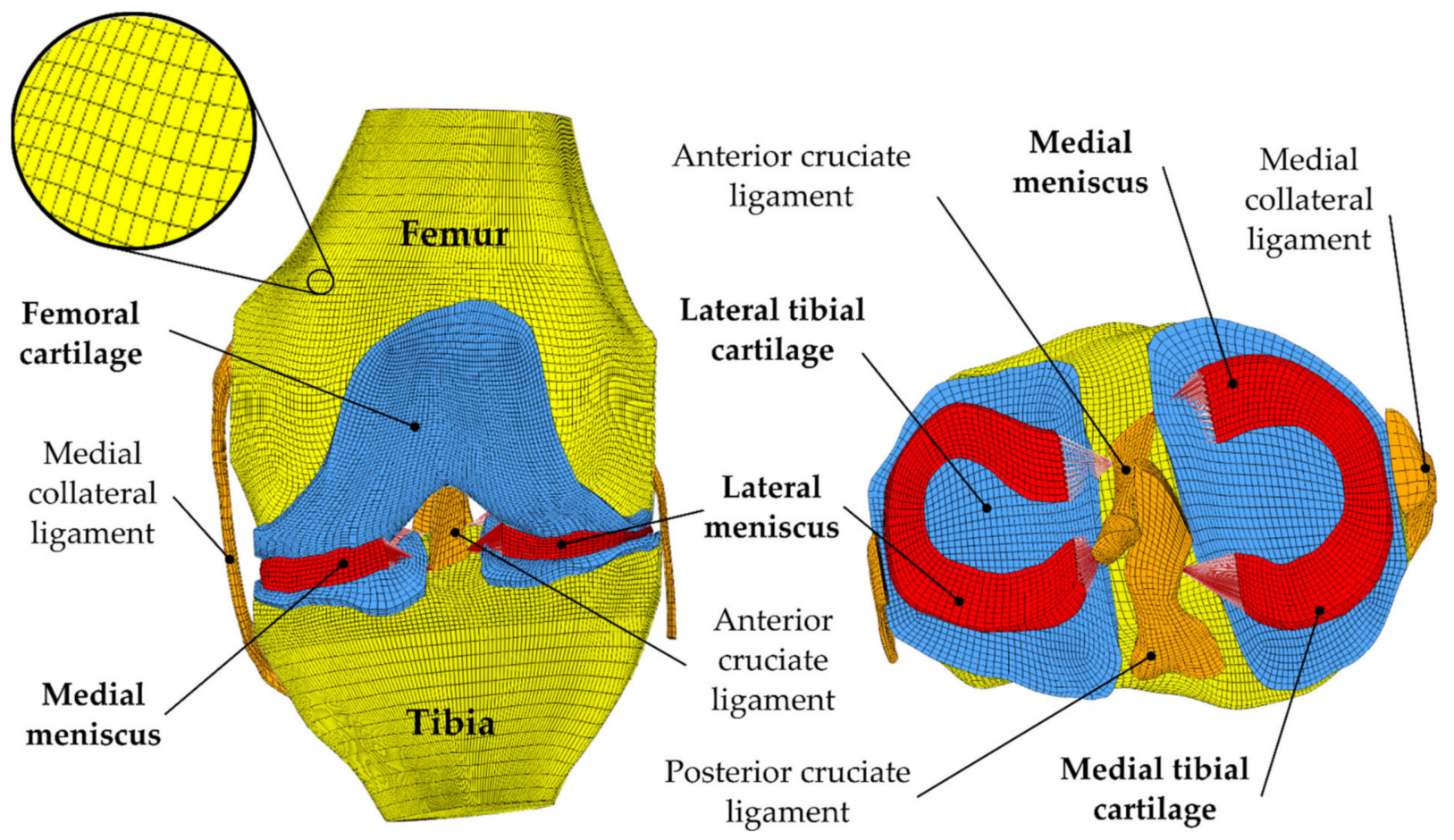

Figure 4. Finite element mesh of the knee joint using hexahedral elements [52]. This model has been used in various investigations and is freely available at https://simtk.org/projects/openknee (accessed on 13 October 2021).

Usually, meshing algorithms create an accurate mesh by controlling the size and type of elements $[53,54]$. These meshing tools are found in commercial and open-source software. Commercial meshers include HyperMesh (Altair Inc., Troy, MI, USA) and others contained in FEA software such as ABAQUS (SIMULIA, Providence, RI, USA) or ANSYS (Ansys, Canonsburg, PA, USA). Open-source meshers include Gmsh, SALOME, and MeshLab. On the other hand, it is also possible to use custom algorithms. For instance, Rodriguez-Vila et al. [33] developed an automated meshing tool for knee cartilages and menisci, whose inputs are 3D geometries in .stl format, to generate hexahedral meshes of tissues in $\sim 200 \mathrm{~s}$. These meshes matched well with the original geometries, with reliable discretization and time savings in subject-specific models of the knee joint. That algorithm and eight knee meshes from the OAI can be freely reached at https:/ /im.engr.uconn.edu/downloads.php (accessed on 24 November 2021).

This stage of the FEA workflow can be expedited in other ways. For example, Baldwin et al. [45] accelerated the meshing process by working directly on the set of medical images, avoiding the segmentation stage. They proposed to control the shape of the mesh via key nodes (handles) distributed in the mesh. The user fits hexahedral meshes of femoral, tibial, and patellar cartilages directly to the morphology of the patient in $\sim 1.5 \mathrm{~h}$. This 
template-based approach allows for control of the element type and mesh quality, although it still depends on the time and expertise of users to identify the tissue contours on images.

In a final example, combining the study of knee geometry variability and fast mesh generation, Rao et al. [49] developed a method to rapidly define knee FE models. They used MRI and experimental data from 20 cadaveric knees and used principal component analysis (PCA) to identify what geometric characteristics added more to the variability between subjects. A template mesh from an average knee geometry was fitted to different subjects using handles to control node subsets. The element type for bones was linear triads and linear hexahedral elements were used for cartilage. They found that the size and the relative position and alignment (tibial anterior-posterior) of knee structures in a loaded state were the main sources of variability. This method allows generating knee models with realistic geometries of virtual subjects useful for implant design.

\subsubsection{Material Constitutive Models}

The constitutive models are chosen according to the objective of the study [59-62], and the mechanical parameters should be selected to mimic real tissue behavior based on the experimental data.

Cartilage. Articular cartilage can be described as a biphasic fibril-reinforced material. This tissue reacts differently under tensile and compressive forces. In addition, it exhibits a time-dependent behavior caused by two mechanisms: in compression, mainly due to fluid exudation, and in tension, mainly due to the viscoelasticity of the solid phase, particularly collagen fibrils.

The simplest constitutive model defines this tissue as an isotropic homogeneous elastic material, indicating it mimics only one time-point from the stress-relaxation curve. As such, it should be used with caution to model only instantaneous and equilibrium tissue responses [63,64]. For time-dependent behavior, cartilage has been modeled using solid viscoelastic $[65,66]$ and biphasic formulations $[67,68]$. Biphasic models are based on poroelasticity theory, developed by Biot [69], and mixture theory, developed by Mow et al. [70-72]. Both theories consider a biphasic material composed of incompressible solid and fluid phases and lead to equivalent solutions [73]. There, the volumetric changes in tissue are explained by the net fluid flux through tissue boundaries. Subsequent cartilage models captured both relaxation mechanisms, with biphasic formulations including a viscoelastic solid phase [74-77]. Further descriptions allow for modeling of the anisotropy caused by the collagen fibril network as well as the depth-dependent heterogeneities in water and the proteoglycan (PG) and collagen contents [78-80]. Finally, since PGs induce cartilage swelling due to negative charges, the most complex descriptions include swelling [81,82] and triphasic [83,84] models.

The site-specific distributions of material constituents in cartilage may impact its mechanical response or serve as a measurement of tissue integrity. Researchers can use imaging techniques such as quantitative MRI (qMRI) to compute such distributions [85-87]. At the organ scale, Räsänen et al. [86,87] studied the effect of in vivo fixed charge density (FCD) distribution in knee cartilage under different loading conditions. To do so, they obtained the FCD distribution using ${ }^{23} \mathrm{Na}-\mathrm{MRI}$ and used a fibril-reinforced poroviscoelastic with swelling effect formulation for cartilage and menisci. First, in [86], they compared the MRI-based tibial cartilage deformation before and after the standing period with the patient bearing half of their weight for 13 min statically. They concluded that using a subjectspecific FCD content differs from using a constant value or a generic depth-dependent distribution from the literature. Second, in [87], they simulated the stance phase of the gait modeling combinations of different FCD contents and collagen network stiffnesses. Results showed that combining the lowest FCD content with the softest collagen network, as found in knee OA patients, resulted in a considerable reduction in cartilage mechanical capabilities. In addition to MRI-based solutions, ultrasound techniques can also estimate tissue characteristics in vivo, such as thickness and stiffness [88-91], but quantifying other material properties such as permeability is still restricted to in vitro setups. 
Sometimes, the aim of the study can be reached with an intermediate complex material formulation. For instance, by using a biphasic transversely isotropic description, different authors were able to reproduce experimental cartilage stress-relaxation tests [92-94]. Bolcos et al. [95] used a biphasic transversely isotropic model [60] to identify zones of knee cartilage susceptible to post-traumatic osteoarthritis. This demonstrated that constitutive models with this complexity level could simulate realistic responses of the tissue.

Meniscus. Regarding material models for meniscal tissue and meniscal attachments, similarly to cartilage, a variety of constitutive models have been proposed, from isotropic elastic to biphasic elastic reinforced with fibrils [96-101]. Párraga et al. [99] compared two biphasic fibril-reinforced tissue models to justify using a complex or simpler distribution of meniscus constituents. They compared depth-dependent and homogenized distributions for collagen, water, and PGs in an axisymmetric model of the knee joint, including cartilage and meniscus. Results showed no significant differences in the cartilage fibril strain between the models. Thus, the authors suggested that using a homogenous distribution of meniscus constituents yields trends in stresses and strains similar to those found when using a depth-dependent one.

Ligament and tendon. Similarly, the ligament tissue can be described as a complex material and different constitutive models have been used to model it [37,63,102-105]. With respect to this tissue, Orozco et al. [106] studied the impacts of using different geometrical representations and formulations of ligaments on knee joint mechanics. They simulated the gait cycle of a 3D knee joint, including the anterior and posterior cruciate ligaments (ACL, PCL), lateral and medial collateral ligaments (LCL, MCL), quadriceps, patellar tendons, menisci, and patellar, femoral and tibial cartilage. They formulated ligaments as springs, elastic, hyperelastic, poro-hyperelastic, and fibril-reinforced poro-hyperelastic. Results suggested that, at certain time points of functional activities, simpler material formulations could mimic the mechanical response obtained with more complex models. This approach saves time in the pre-processing stage, by skipping the segmentation of ligament geometry, and in the processing stage, since solving models using springs is faster than using complex fibril-reinforced poro-hyperelastic formulations.

Bone. Different authors model bone tissue as a homogenous and solid elastic material even though its heterogeneous and biphasic nature is known [28,107-110]. Moreover, the boundary between bone and cartilage is not abrupt. In this region we find transition zones between cartilage, calcified cartilage, subchondral bone, and trabecular bone. Stender et al. $[28,108]$ identified the importance of these transition zones when modeling OA in bone and explained the mechanical crosstalk between the different tissues. Nevertheless, when the interest is focused on cartilage only, bones have been often modeled as rigid bodies in many studies. Through this assumption, researchers avoid including the specific geometry of bones and only consider their constraining effect as boundary conditions such as rigid and impermeable regions [24,111].

\subsubsection{Subject-Specific Motion and Loading}

Once the domain is discretized and the constitutive material models are chosen, the next step is to define the boundary conditions and loading.

Usually, this subject-specific information is obtained via motion capture. This task can be conducted using infrared cameras and reflective markers, using inertial measurement units (IMUs), or using video recordings and AI. In addition to motion, the ground reaction forces (GRFs) are recorded with pressure sensors, and the muscular activation is captured via electromyography (EMG). Then, joint motions, moments, contact forces, and muscle forces in the knee can be estimated using inverse kinematics via musculoskeletal modeling [24,112-115]. This process is facilitated with software such as AnyBody (AnyBody Technology, Aalborg, Denmark), Vicon (Vicon Motion Systems Ltd., Oxford, UK), and OpenSim [116]. Other options to estimate these variables in the knee involve AI, where physics-based models are replaced by trained machine learning models [42,117-120]. In these models, knee loading patterns (e.g., joint forces and moments) can be predicted from 
measured variables (e.g., marker trajectories, GRFs, and EMGs) by organizing the input information into matrix form and optimizing a set of parameters to correlate it with the desired response. Some machine learning methods are better than others depending on the type of data and the objective of the study $[117,121]$.

The implementation of mechanical loadings in knee joint models is essential for estimating the mechanical response of cartilage, menisci, ligaments, and tendons $[3,24]$. However, generating subject-specific data from different physical activities can be a cumbersome task that might take weeks or months to complete. Thus, for expediting the implementation of the loading conditions, some authors have estimated them by scaling a mean gait pattern to different patients according to body weight (BW) [122], using experimental data or using musculoskeletal models [113,114]. Another option would be using machine learning approaches with few inputs. For instance, De Brabandere et al. [123] used a mobile phone on 10 hip OA patients to estimate the hip and knee joint impulses through different exercises. Results suggested that they were able to specify the hip impulse in patients differently from a population-based average. However, the pipeline they proposed should be improved for better accuracy.

The exact locations of tendons and ligaments in knee FE models are usually approximated, affecting the kinematics and kinetics of simulations [111,124,125]. This is due to the simplified geometry representation of the tissues and the variability in the insertion point locations from medical images $[125,126]$. In this regard, Harris et al. [1] studied knee laxity by combining experimental data and FEA. They analyzed four cadaveric knees and optimized the location of the insertion points, the pre-strain, and the stiffness of the ligaments based on one-to-one validations. The authors acknowledged the difficulties of the process and made the experimental data and the optimized model parameters freely available.

\subsubsection{Model Configuration}

This refers to the decisions regarding what knee structures to include in the models, what level of detail is needed, and what assumptions will be included in the final model. Rooks et al. [126] showed how this decision-making process results in different strategies to answer the same research question concerning the knee joint using FEA. In that study, five teams developed FE models of two knees to simulate a passive knee flexion between 0 deg and $90 \mathrm{deg}$, considering the patellofemoral and tibiofemoral joints. In general, the teams had similar workflows, although they integrated some knee structures differently. In brief, the teams considered bones as rigid bodies, just one included deformable cartilages, one of them excluded the menisci, and one of them excluded the tendons. The time required to solve the models varied between $30 \mathrm{~min}$ and $9 \mathrm{~h}$.

Sometimes, a multi-scale model is needed to answer the research question [125,127-131]. In these cases, researchers look for the concurrent effects of mechanical stimuli through different physics scales [131]. For instance, it is possible to even simulate the chondrocyte mechanical environment within cartilage under unconfined compression [132] or gait cycle loading in healthy and meniscectomized knees [129]. In more detail, Esrafilian et al. [130] combined FEA with musculoskeletal models assisted by EMG to develop a subject-specific knee joint model. They formulated bones as rigid bodies, cartilage as fibril-reinforced poroviscoelastic, menisci as fibril-reinforced poroelastic, and ligaments as non-linear springs. The loading corresponded to a gait cycle, and the muscle forces were estimated by an EMG-assisted musculoskeletal model. They performed a sensitivity analysis to study the effect of ligament pre-strain on the mechanical response of cartilage. The results indicated that the pre-strain of ACL, PCL, and MCL highly affected contact forces and contact areas, while it less affected cartilage stresses, fluid pressures, and fibril strains. Thus, the authors recommended being more rigorous in calibrating ligament pre-strain when the interest is the kinematics and kinetics of the joint compared to studies focused on the mechanical response of articular cartilage. Regarding the time, authors spent one month in the pre-processing stage, the FE model ran in $30 \mathrm{~h}$ and the post-processing stage was automated. 
Bolcos et al. [32] explored expediting FE models for potential clinical use in the future. They compared articular cartilage biomechanics between kinetic and kinetickinematic driven knee joint models simulating a gait cycle. In the most complex kinetic model, forces and moments drove the simulation during the stance phase of gait. In the simplest kinetic-kinematic driven model, only forces and rotations were used to control the simulated gait motion. Comparisons between models revealed similar cartilage mechanical responses (i.e., maximum principal stress, maximum principal strain, and pore pressure). In conclusion, combining kinematic and kinetic inputs, which is easier to implement than kinetic alone, saves weeks of workload compared to the most complex model without sacrificing much accuracy.

\subsection{Processing}

At this stage of an FEA, the mathematical problem behind the model is solved using numerical algorithms. This considers the governing equations describing the physics, the discretized domain, the material constitutive models, and the boundary conditions. The inclusion of time-dependent and inertial terms defines what type of analysis (static, transient, or dynamic) should be performed. Depending on the complexity of the model (number of mathematical equations) and the available computational resources, to computationally solve the numerical problem may take from minutes to weeks [133].

There is a variety of specialized software to process complex FE models. For instance, ABAQUS (SIMULIA, Providence, RI, USA) is a popular software utilized for FEA in biomechanics. This commercial software enables incorporating user-defined (UMAT) subroutines to describe constitutive models, which is a common necessity for developing new material formulations. In addition, ANSYS (ANSYS, Canonsburg, PE, USA) and COMSOL (COMSOL, Stockholm, Sweden) are commercial software widely used for biomechanics modeling. On the other hand, FEBio (FEBio Software Suite, Salt Lake City, UT, USA) is an open-source and freely available software focused on solving problems in biomechanics and is particularly focused on solving biphasic problems [134,135].

\subsection{Post-Processing}

This is a central stage when results of the FEAs are interpreted. Adequate postprocessing gives insights into the assumptions made at the beginning of the research and supports further hypotheses.

There are different ways to analyze the results. For example, appropriate fringe plots offer a visual translation of the intensities of variables such as deformations and stresses, and vector fields and streamlines are appropriate to describe principal tensor components and fluid motions [136]. In addition, figures and statistics are mandatory for qualitative and quantitative evaluations of tendencies and correlations, respectively. For these postprocessing tasks, many researchers trust MATLAB (The Mathworks, Natick, MA, USA), since it offers a wide variety of functions for extensive analyses by manipulating matrices, and statistical software such as SPSS (IBM SPSS Statistics, Armonk, NY, USA) and Stata (StataCorp LP, College Station, TX, USA).

Furthermore, it is commonly necessary to understand the effect of parameter variations on the model outputs, such as material parameter uncertainties on resultant displacements or stresses. These sensitivity studies, which require iterative processes, are accomplished by linking different software and programming languages. For example, programing routines in MATLAB, Isight (SIMULIA, Providence, RI, USA), or Python run a model a certain number of times or look for the optimization of an objective function using the FEA software results $[1,24,80]$. This kind of analysis is time-demanding but elucidates important conclusions, e.g., indicating what are the parameters that most affect the model response [115,137-139]. Once these studies are accomplished, the modeling can be improved by considering variations in only those identified parameters, increasing the reliability of the final models, and drawing suggestions concerning the tissue properties that should be more carefully determined. For instance, Dhaher et al. [2] quantified the vari- 
ation in patellofemoral kinematics and contact stress caused by uncertainties from material properties of LCL, MCL, PCL, ACL, and lateral (LPL) and medial (MPL) patellofemoral ligaments by combining FEAs and Monte Carlo simulations. They found that uncertainties in the ACL material parameters caused high variation in the patellofemoral kinematics, and even larger effects compared to tissues of the patellofemoral joint.

\subsection{Onset and Progression of $O A$}

Several factors are associated with increased risk of developing OA, such as obesity, diabetes, genetics, age, and gender $[7,140,141]$. In addition to these factors, joint injuries may cause lesions in articular cartilage, contributing to the development of post-traumatic OA $[21,95,142]$. However, the causative mechanisms for the initiation and progression of OA are not fully understood.

FE models have been used to test hypotheses regarding the OA mechanisms at different scales. On the one hand, at the tissue level, researchers have studied the effects of the depletion of cartilage constituents on the mechanical response of the tissue, such as reaction forces and displacements in unconfined compression relaxation tests of cartilage samples [143-145]. Others investigated the cross-talk between tissues that could address tissue remodeling when the mechanical environment changes [28]. Mechanobiological models have also intended to explain the interplay of tissue constituents with the degradation of cartilage, including cell signaling to modify the mechanical response [21,146-148].

On the other hand, at the joint level, researchers have simulated a variety of diseased conditions. These studies include investigations of the effect of size and location of cartilage superficial defects on strain and stress concentrations [139], the effect of knee structures' relative orientation on cartilage thinning [149] and the effect of collagen disorganization on the load-bearing functions of cartilage [150,151]. Moreover, to understand possible OA pathways, Orozco et al. [146] developed a mechanobiological knee joint model to predict FCD alterations involving cartilage lesions in ACL ruptured and reconstructed patients. Their results were contrasted with quantitative longitudinal changes observed in MRI maps. That study postulated that excessive shear deformations and fluid velocity are responsible for the FCD loss in the injured cartilage tissue. In addition, related to an ACL deficient knee, Shim et al. [148] studied the subchondral bone remodeling after simulating a three-month walking loading condition. They used a multiscale approach and compared the simulated cell signaling between healthy and ACL deficient states, which would drive bone remodeling and the subsequent cartilage inflammatory response. Results showed higher strain at the zone of calcified cartilage and a higher concentration of proinflammatory mediators in the ACL deficient knee compared to the healthy condition.

Aiming for future clinical applications of knee FEAs, Liukkonen et al. [152] implemented a FE-based method to estimate the onset and progression of knee OA in 21 knees. In their method, the cartilage collagen network was assumed to soften when a stress threshold for failure was exceeded, mimicking the tissue degradation. Models included subject-specific MRI-based geometries only for the medial compartment, based on the OA prevalence, and a typical joint loading share between the medial and lateral sides. The menisci were subtracted from the models, but their load-bearing effect was considered when applying the generic gait loading condition (scaled with subject body weight) through the tibiofemoral joint. The researchers simulated the future cartilage degradation from a baseline condition when all subjects were healthy, with a Kellgren-Lawrence grade of 0 (KL0). Then, they verified the predictions against OAI data by classifying follow-up KL grades of the 21 knees in healthy (KL0) and diseased (KL2 and KL3) groups. In order to include more subjects efficiently, Mononen et al. [26] proposed a FEA template-based method for the above approach (Figure 5). They parameterized the model geometries to scale a template mesh from an atlas of 21 subjects to different individuals. In addition, they used stress thresholds for damage linked to the age of the subject [140]. By this method, the time to create a subject-specific model was reduced from one week to $2 \mathrm{~min}$. Results showed that the approach had promissory capabilities to classify patients into four different 
KL grade groups (KL0, KL2, KL3, KL4) based on the baseline information. They verified their method with the same OAI subjects used in [152].

\section{a. Subject-specific approach}

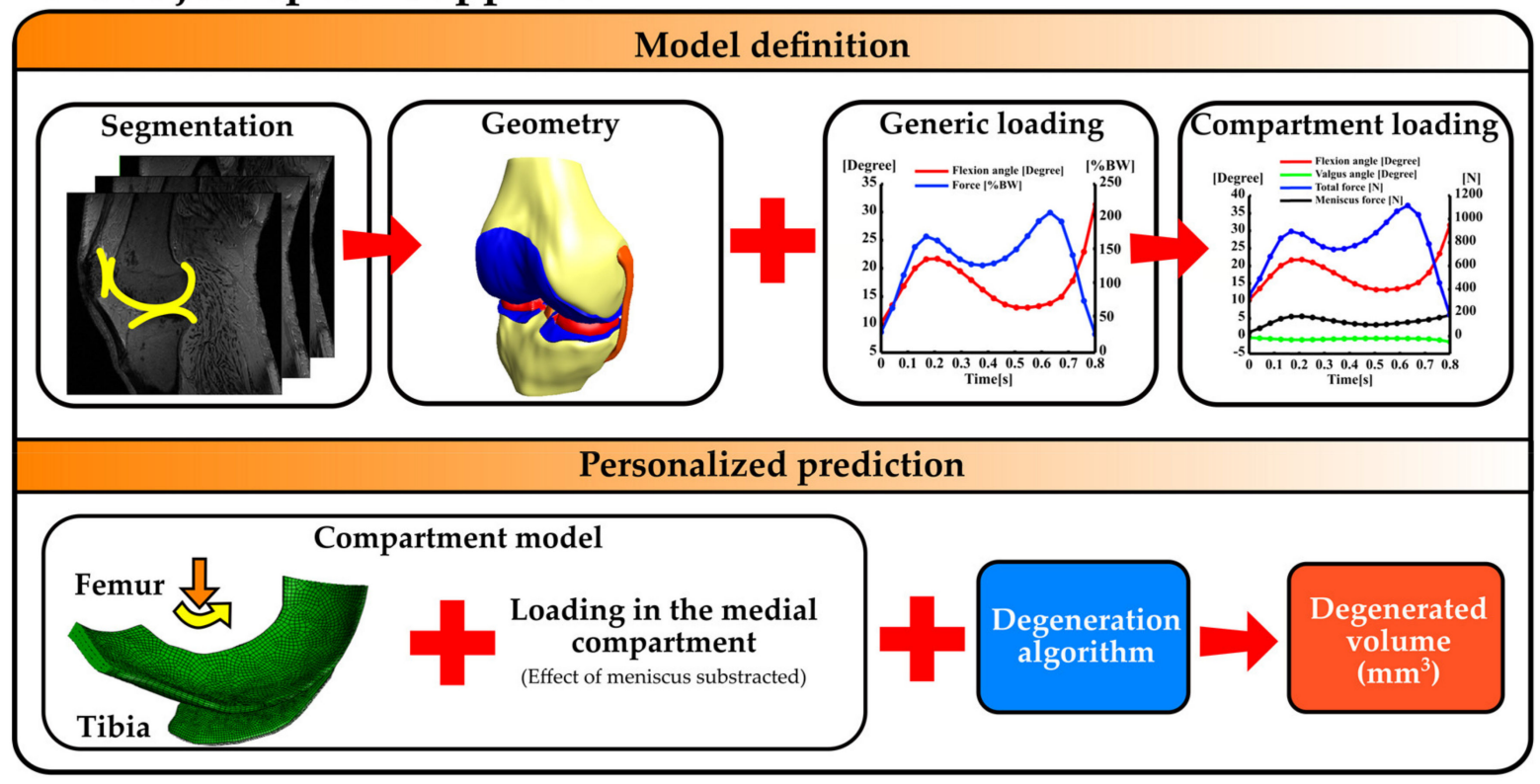

\section{b. Template-based approach}

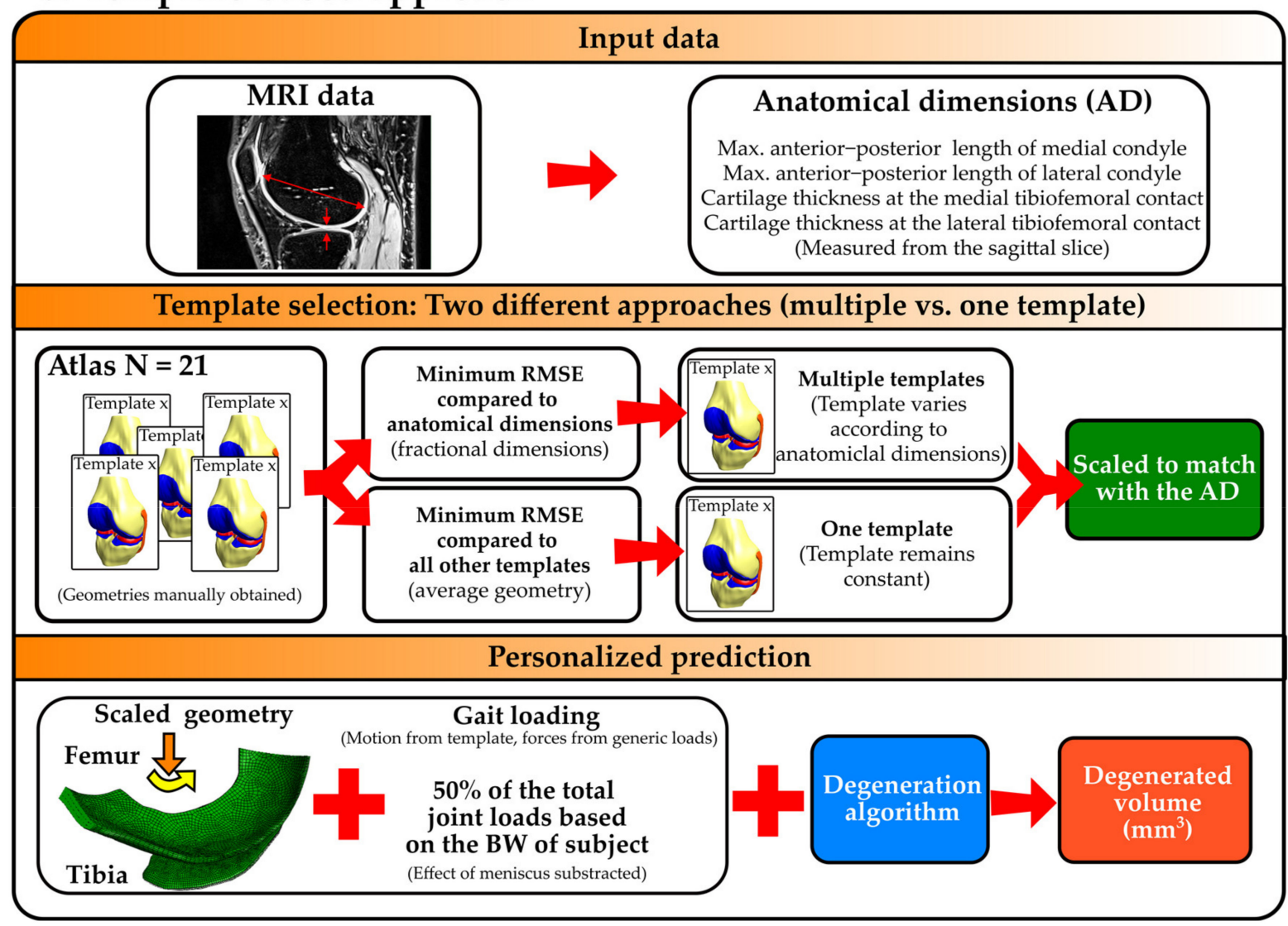

Figure 5. Workflow of an atlas-based approach to study the progression of knee OA [22]. This approach considered the medial compartment only and subtracted the load-bearing fraction of the meniscus from the axial force. (a) The traditional way to model a specific knee and (b) the template-based approach. 


\subsection{Verification and Validation}

When developing new models or approaches, they should be verified and validated before the results they produce can be trusted. The verification can be completed by comparing the computational model results with those of similar previous works. The reason behind this is to confirm that the new models offer logical results. Subsequently, the validation is crucial for demonstrating the capabilities of the model to reproduce and predict experimental results. The source of experimental data for validations includes in vitro and in vivo experiments. In vitro experiments include testing of tissue explants and complete joints from cadavers. Commonly, stress-relaxation test data with several strain steps are used to calibrate and validate material parameters of cartilage, especially for complex material models $[63,104,153,154]$. In vivo experiments can include data from instrumented knee prostheses (with a force sensor) after total knee replacement (TKR) surgery, and data from non-invasive techniques such as MRI [155], and external transducers such as pressure sensors, electromyography, and markers for gait analysis $[24,124,156]$.

Parameters for the validation of musculoskeletal and FE joint models include in vivo forces through tibiofemoral and patellofemoral joints [3], cartilage deformations [155,157,158], and displacements of the patella and menisci, which are variables useful for the assessment of musculoskeletal disorders [13,111,159-161]. In this regard, MRI and fluoroscopy have been used to study the relative motion of internal structures of the knee in vivo [162-165]. For instance, Li et al. [166] combined dual fluoroscopy with SSM to evaluate the kinematics of the knee joint. The dual fluoroscopy combined with the SSM technique was used to automatically calculate subject-specific geometries and the relative motion of bony structures. They studied the kinematics of the stance phase of three subjects walking at 3.2 kilometers per hour. Their method produced root mean square (RMS) errors as high as $1.77 \mathrm{~mm}$ in geometries, 3.3 degrees in rotations, and $2.4 \mathrm{~mm}$ in displacements, compared to a CT-based method. This study evaluated an approach to expedite the kinematic analysis of subjects and reduce radiation exposure compared to using CT scans.

Regarding knee OA prediction models, they are currently verified and validated against qualitative and quantitative data. Qualitative assessments involve, for example, comparisons of the location of damage and morphology changes in cartilage $[95,149,167]$. On the other hand, quantitative assessments are more challenging due to experimental inaccuracies and difficulties in analyzing clinical image data properly. At a local tissue level, the OA Research Society International (OARSI) proposed grading the tissue damage based on histologic characteristics, resulting in a six-grade scale [168,169]. At a whole-organ level, other grading systems can be used. They include the Collins grading system [168], which classifies tissue characteristics by direct observation of the tissue, commonly with the patient under surgery or autopsy. A recent study [170] found a high correlation $(R=0.887)$ between OARSI grading scores and Collins scores using 22 cartilage samples from six donors, indicating an equivalence between both physical scale evaluations.

For conservative clinical practices, performing biopsies to collect tissue samples could be detrimental to the integrity of the joint. Thus, comparison against clinical history data can be considered the gold standard $[18,20,22,171,172]$. Here, simulated predictions for OA development, estimated with the information obtained at the baseline and model outcomes, are compared against follow-up data (changes compared to baseline) utilizing quantitative data obtained from clinical imaging. For these comparisons, for instance, researchers have access to the Osteoarthritis Initiative (OAI) database, available for public access at https:/ / nda.nih.gov / oai / (accessed on 26 November 2021), which offers information on 4796 patients, followed during eight years [173]. This database includes various data types such as imaging with X-rays and MRI, biomarkers, Western Ontario and McMaster Universities Osteoarthritis Index (WOMAC), Knee Injury and Osteoarthritis Outcome Score (KOOS) assessments, MRI Osteoarthritis Knee Score (MOAKS), Whole-Organ Magnetic Resonance Imaging Score (WORMS) and Kellgren-Lawrence grades (KL). 


\section{Discussion}

Computational analyses in biomechanics and medicine are valuable for surgery planning, medical device design, and understanding and preventing disease progression [174]. The ability to predict the initiation and progression of diseases would yield many benefits for patients, society, and the economies of countries. In this review, we focused on computational finite element analysis (FEA) aiming for an understanding of knee OA mechanisms and improvements for speeding up subject-specific models and simulations.

Regarding planning surgical procedures, FEAs can be utilized to understand the effects of meniscectomies on cartilage stress distributions [175,176]. Zhang et al. [176] simulated the effects of degenerative and radial tears of meniscus and meniscectomies on tissue stresses and displacements. Results indicated that performing a medial meniscectomy increases stresses in remaining tissue. Another application is design of surgical procedures for correcting extra- and intra-articular deformities associated with knee OA. Ji et al. [177] proposed combining an opening-wedge high tibial osteotomy (OWHTO), related to extraarticular deformities, with a tibial condylar valgus osteotomy (TCVO), related to intraarticular deformities. FEAs and experimental tests on synthetic bone models revealed a comparable strength of the novel procedure to the currently used OWHTO procedure.

In addition to surgical interventions, conservative options, such as gait retraining and weight loss, could also be aided and encouraged by computational models to prevent disease progression [22,178-180]. Richards et al. [181] showed the impact of a six-week gait retraining program on 16 subjects. They recommended specific gait retraining to reduce the knee adduction moment (KAM) in patients with medial knee OA. They used musculoskeletal modeling to estimate moments at the knee joint and assess the effect of the toe-in pattern trained during gait. For training, they used an instrumented treadmill with graphical interfaces to provide feedback to the patient during the trials. Results suggest the program effectively reduced the KAM in medial knee OA patients even six months after the training. The authors recommended complementing their study with additional FEA analyses. These variations in the KAM can easily be implemented in FEA models to estimate the consequence of these rehabilitation protocols on the knee joint tissues.

As shown, FEA is currently utilized and recommended for complementing other approaches. Thus, for subject-specific analysis towards clinical applications in OA, we identified that certain phases in the current pipeline can be accelerated. In pre-processing, several studies have proposed solutions for rapid image segmentation to obtain the patientspecific geometry of the joint and procedures for automated meshing. However, no approach has been implemented to rapidly indicate subject-specific input loadings, nor biomechanical adaptations of the patient, e.g., gait pattern alterations caused by pain during OA worsening. In this regard, there are proposals for rapid loading estimation that can be later linked with those focused on rapidly obtaining the knee geometry and mesh. For instance, Pizzolato et al. [180] implemented a workflow for the real-time estimation of the knee medial tibiofemoral contact force. Their method used a physics-based electromyogram-driven neuromusculoskeletal model. Burton et al. [117] compared different machine learning algorithms to predict the activation of muscles around the knee as well as the knee and hip contact forces. They found that a recurrent neural network (RNN) offered the best predictive capabilities. The RNN was able to mimic the outcomes of musculoskeletal modeling, which is a physical-based method.

Regarding accelerating the processing stage, not much information was given in the literature within our scope. However, based on our experience, these FE models can be solved utilizing parallel computing on powerful computer servers, although limitations arise related to licensing of commercial software. Thus, it would be valuable to hear from researchers in this field regarding their experiences and suggestions for alternative strategies.

For expediting the post-processing, it is highly dependent on the research question. When studying the effect of uncertainties in models, e.g., from material properties, the type of parametric study chosen will considerably impact the time necessary for the completion of the analyses [35]. On the other hand, when iterative processes are not needed but large 
cohorts are studied, automating the analysis can easily be implemented by linking FE software outputs with programming languages such as Python and MATLAB.

To verify OA prediction results, the best approach is comparing predictions against degenerative tissue changes obtained from clinical imaging during a follow-up period. This can be a challenging task since the analysis of morphological changes may be subjective and takes a great deal of time, especially when data from thousands of subjects are required. This exposes the necessity for novel methods to produce objective data to verify prediction results. As an example to overcome that limitation, automated approaches to measuring cartilage thickness from clinical image data have been developed [182]. This method could be utilized to generate feasible data (changes in cartilage thickness between baseline and follow-up imaging) to verify novel degenerative and adaptive algorithms.

To account for patient-specific tissue composition information to study knee OA, imaging is a well-developed field in medicine, with continuous improvements in equipment and post-processing tools [183], that can be linked to the FEA workflow. Mapping MRI markers have demonstrated good correlations with early OA location and progression. These markers include $T_{2}$ and $T_{1 \varrho}$ relaxation times, which are related to water content, collagen distribution, and proteoglycans density [184-186], which can be considered as FE model inputs. Early in this review, we highlighted how Räsänen et al. [86,87] used ${ }^{23} \mathrm{Na}$-MRI information as input data for FEAs of the knee. Though the distribution of MRI parameters can be transferred into the distribution of mechanical parameters in FE models, the workflow behind this translation is time-consuming. Recent studies have made efforts to rapidly produce MRI marker distributions [187,188], but the approach to automatically translating them into FE models is still missing. As subchondral bone has a contribution to the development of knee OA [189,190], it should also be considered when making more accurate FE models to predict disease progression. In this line of research, Hirvasniemi et al. [191] developed a methodology to correlate bone density and texture with OA progression from $X$-ray images with low clinical post-processing, offering a rapid and low-cost analysis. Bone information can be incorporated in the FEA workflow, either for site-specific inputs or for verification purposes.

As mentioned earlier, in vivo estimation of tissue mechanical properties in the knee joint is challenging, making it difficult to include complex patient-specific tissue information in FE models. However, in vivo tissue stiffnesses can be estimated using techniques including MRI [158,192], based on strain-stress relationships, and ultrasound [88], based on wave velocities in media. Wu et al. [193] used shear wave elastography (SWE) to determine Young's moduli of muscles, ligaments, and tendons around the knee joint. The study involved 50 female and male subjects, divided into groups aged 21-30, 31-40, 41-50, and above 51 years. The authors found higher values for males and decreasing values for older subjects, but the mechanisms behind the decrease in the mechanical properties due to aging are still unknown. In the future, these unmodifiable characteristics (age, gender) of patients could be considered in models through correlations and by utilizing statistical methods or machine learning algorithms, together with in vivo properties measured using noninvasive techniques.

FEA approaches coexist with other computational methods to study OA. For instance, several studies have utilized mathematical models of the patellofemoral joint (PFJ), assuming the joint as a two-dimensional mechanism, to determine contact areas and forces resulting in contact pressure distributions [194-197]. This approach has demonstrated good results by relating the biomechanical parameters of the PFJ to OA. These studies highlight that this method works rapidly compared to FEA, although the range of movement is limited to the sagittal plane and the articular cartilage is modeled as an isotropic linear elastic material. Similarly, discrete element analysis (DEA) has been utilized to model hip and knee joint contacts [198-200]. DEA demonstrated a similar contact response compared to FEA models of the hip joint [199], and similar contact pressure distributions to experimental measurements in the PFJ [198]. DEA does not require a volumetric mesh, using shell elements instead, with which elastic springs are associated, relating to the thickness of 
tissue (cartilage) and elastic properties (Young modulus and Poisson ratio). In this method, contact is enforced by the springs when penetration of surfaces is detected. DEA offers solutions in seconds, although cartilage is assumed to be isotropic and linear elastic.

Statistical and AI tools are active fields to study knee OA. From this point of view, Halilaj et al. [20] modeled the longitudinal progression of knee OA based on OAI data of medical visits of 1243 patients, including X-ray measurements and WOMAC scores. With this information, they built regression models to classify subjects into different clusters according to the observed radiographic and pain progressions. Their approach was able to predict radiographic progression utilizing the information from two visits separated by one year and predicted the pain progression using only one observation. Kokkotis et al. [121] reviewed many applications of machine learning related to knee OA. These covered the prediction of disease onset and progression based on a variety of patient characteristics [201], correlation of features that could allow the early diagnosis of knee $\mathrm{OA}$, and techniques for fast medical image segmentation [202] and classification [203]. However, AI methods cannot be used to simulate the effects of clinical interventions on the mechanics of the knee, including the subsequent adaptation processes in articular cartilage.

Based on the investigations mentioned in the present review, studying knee OA via FEA is becoming faster and more reliable in terms of model input (pre-processing). Some gaps and difficulties are being filled and solved for translating these exploratory advances to the clinical environment. We believe the fields of active research related to studying knee OA via FEA would be:

- Automate pre-processing tasks using a minimum amount of information (geometry generation and loading specification);

- Incorporate site-specific tissue composition and mechanical properties;

- Develop accurate algorithms for OA prognosis (theory and validation);

- Develop efficient multiscale modeling methods (from joint to tissue level);

- Combine advances in FEA, musculoskeletal modeling, and AI.

Thus, in the near future, coming investigations will efficiently combine machine learning approaches, faster and more affordable imaging techniques for rapidly generating subject-specific geometries and meshes, and personalized mechanical inputs such as tissue properties and loading scenarios. Similar phenomena will occur within processing and post-processing with accelerated task performance via coupling analysis methods (e.g., FEA and AI). In the long term, these advances would enable novel treatment management strategies to delay or prevent the progression of knee OA. Personalized predictions will offer a new route to optimize the most cost-effective therapy option. Furthermore, visual information from personalized prognoses and the effects of different interventions could motivate and commit patients to suggested treatment.

Author Contributions: Conceptualization, methodology, writing, and data acquisition: A.P., G.A.O., R.K.K., J.J.G. and M.E.M.; funding acquisition, G.A.O., R.K.K. and M.E.M. All authors have read and agreed to the published version of the manuscript.

Funding: This research was funded by the Academy of Finland (grants 324994, 328920), the Sigrid Juselius Foundation, and the Swedish Research Council (2019-00953 - under the frame of ERA PerMed).

Institutional Review Board Statement: Not applicable.

Informed Consent Statement: Not applicable.

Data Availability Statement: Not applicable.

Acknowledgments: To Universidad del Valle and the University of Eastern Finland, for bringing us documentary resources to carry out this work in a good timeframe.

Conflicts of Interest: The authors declare no conflict of interest. The funders had no role in the design of the study; in the collection, analyses, or interpretation of data; in the writing of the manuscript, or in the decision to publish the results. 


\section{References}

1. Harris, M.D.; Cyr, A.J.; Ali, A.A.; Fitzpatrick, C.K.; Rullkoetter, P.J.; Maletsky, L.P.; Shelburne, K.B. A Combined Experimental and Computational Approach to Subject-Specific Analysis of Knee Joint Laxity. J. Biomech. Eng. 2016, 138, 1-8. [CrossRef]

2. Dhaher, Y.Y.; Kwon, T.; Barry, M. The effect of connective tissue material uncertainties on knee joint mechanics under isolated loading conditions. J. Biomech. 2010, 43, 3118-3125. [CrossRef] [PubMed]

3. Fregly, B.J.; Besier, T.F.; Lloyd, D.G.; Delp, S.L.; Banks, S.A.; Pandy, M.G.; D’Lima, D.D. Grand Challenge Competition to Predict In Vivo Knee Loads. J. Ortopaedic Res. 2014, 30, 503-513. [CrossRef] [PubMed]

4. Ali, A.A.; Harris, M.D.; Shalhoub, S.; Maletsky, L.P.; Rullkoetter, P.J.; Shelburne, K.B. Combined measurement and modeling of specimen-specific knee mechanics for healthy and ACL-deficient conditions. J. Biomech. 2017, 57, 117-124. [CrossRef] [PubMed]

5. Litwic, A.; Edwards, M.H.; Dennison, E.M.; Cooper, C. Epidemiology and burden of osteoarthritis. Br. Med. Bull. 2013, 105, 185-199. [CrossRef]

6. Gersing, A.S.; Schwaiger, B.J.; Nevitt, M.C.; Joseph, G.B.; Chanchek, N.; Guimaraes, J.B.; Wamba, J.M.; Facchetti, L.; McCulloch, C.E.; Link, T.M. Is weight loss associated with less progression of changes in knee articular cartilage among obese and overweight patients as assessed with MR imaging over 48 months? Data from the osteoarthritis initiative. Radiology 2017, 284, 508-520. [CrossRef]

7. Neogi, T.; Zhang, Y. Epidemiology of Osteoarthritis. Rheum. Dis. Clin. N. Am. 2013, 39, 1-19. [CrossRef] [PubMed]

8. Vos, T.; Flaxman, A.D.; Naghavi, M.; Lozano, R.; Michaud, C.; Ezzati, M.; Shibuya, K.; Salomon, J.A.; Abdalla, S.; Aboyans, V.; et al. Years lived with disability (YLDs) for 1160 sequelae of 289 diseases and injuries 1990-2010: A systematic analysis for the Global Burden of Disease Study 2010. Lancet 2012, 380, 2163-2196. [CrossRef]

9. March, L.M.; Bachmeier, C.J.M. Economics of osteoarthritis: A global perspective. Baillieres. Clin. Rheumatol. 1997, 11, 817-834. [CrossRef]

10. O'Neill, T.W.; McCabe, P.S.; McBeth, J. Update on the epidemiology, risk factors and disease outcomes of osteoarthritis. Best Pract. Res. Clin. Rheumatol. 2018, 32, 312-326. [CrossRef] [PubMed]

11. United States Bone and Joint Initiative. The Burden of Musculoskeletal Diseases in the United States (BMUS), 3rd ed.; United States Bone and Joint Initiative: Rosemont, IL, USA, 2014; Available online: http:/ /www.boneandjointburden.org (accessed on 5 February 2019).

12. Cram, P.; Lu, X.; Kates, S.L.; Singh, J.; Li, Y.; Wolf, B.R. Total knee arthroplasty volume, utilization, and outcomes among Medicare beneficiaries, 1991-2010. JAMA 2012, 308, 1227-1236. [CrossRef]

13. Englund, M. The role of biomechanics in the initiation and progression of OA of the knee. Best Pract. Res. Clin. Rheumatol. 2010, 24, 39-46. [CrossRef] [PubMed]

14. DeFrate, L.E.E.; Kim-Wang, S.Y.Y.; Englander, Z.A.A.; McNulty, A.L.L. Osteoarthritis year in review 2018: Mechanics. Osteoarthr Cartil. 2019, 27, 392-400. [CrossRef]

15. Nieminen, M.T.; Casula, V.; Nevalainen, M.T.; Saarakkala, S. Osteoarthritis year in review 2018: Imaging. Osteoarthr. Cartil. 2019, 27, 401-411. [CrossRef] [PubMed]

16. Allen, K.D.; Golightly, Y.M. Epidemiology of osteoarthritis: State of the evidence. Curr. Opin. Rheumatol. 2015, 27, 276-283. [CrossRef]

17. Murphy, L.; Schwartz, T.A.; Helmick, C.G.; Renner, J.B.; Tudor, G.; Koch, G.; Dragomir, A.; Kalsbeek, W.D.; Luta, G.; Jordan, J.M. Lifetime risk of symptomatic knee osteoarthritis. Arthritis Care Res. 2008, 59, 1207-1213. [CrossRef]

18. Segal, N.A.; Anderson, D.D.; Iyer, K.S.; Baker, J.; Torner, J.C.; Lynch, J.A.; Felson, D.T.; Lewis, C.E.; Brown, T.D. Baseline articular contact stress levels predict incident symptomatic knee osteoarthritis development in the MOST cohort. J. Orthop. Res. 2009, 27, 1562-1568. [CrossRef] [PubMed]

19. Chan, L.C.; Li, H.H.T.; Chan, P.K.; Wen, C. A machine learning-based approach to decipher multi-etiology of knee osteoarthritis onset and deterioration. Osteoarthr. Cartil. Open 2021, 3, 100135. [CrossRef]

20. Halilaj, E.; Le, Y.; Hicks, J.L.; Hastie, T.J.; Delp, S.L. Modeling and predicting osteoarthritis progression: Data from the osteoarthritis initiative. Osteoarthr. Cartil. 2018, 26, 1643-1650. [CrossRef] [PubMed]

21. Orozco, G.A.; Tanska, P.; Florea, C.; Grodzinsky, A.J.; Korhonen, R.K. A novel mechanobiological model can predict how physiologically relevant dynamic loading causes proteoglycan loss in mechanically injured articular cartilage. Sci. Rep. 2018, 8, 1-16. [CrossRef]

22. Klets, O.; Mononen, M.E.; Liukkonen, M.K.; Nevalainen, M.T.; Nieminen, M.T.; Saarakkala, S.; Korhonen, R.K. Estimation of the Effect of Body Weight on the Development of Osteoarthritis Based on Cumulative Stresses in Cartilage: Data from the Osteoarthritis Initiative. Ann. Biomed. Eng. 2018, 46, 334-344. [CrossRef]

23. Park, S.; Lee, S.; Yoon, J.; Chae, S.W. Finite element analysis of knee and ankle joint during gait based on motion analysis. Med. Eng. Phys. 2019, 63, 33-41. [CrossRef] [PubMed]

24. Shu, L.; Yamamoto, K.; Yao, J.; Saraswat, P.; Liu, Y.; Mitsuishi, M.; Sugita, N. A subject-specific finite element musculoskeletal framework for mechanics analysis of a total knee replacement. J. Biomech. 2018, 77, 146-154. [CrossRef] [PubMed]

25. Mononen, M.E.; Tanska, P.; Isaksson, H.; Korhonen, R.K. New algorithm for simulation of proteoglycan loss and collagen degeneration in the knee joint: Data from the osteoarthritis initiative. J. Orthop. Res. 2018, 36, 1673-1683. [CrossRef] [PubMed]

26. Mononen, M.E.; Liukkonen, M.K.; Korhonen, R.K. Utilizing Atlas-Based Modeling to Predict Knee Joint Cartilage Degeneration: Data from the Osteoarthritis Initiative. Ann. Biomed. Eng. 2019, 47, 813-825. [CrossRef] [PubMed] 
27. Hosseini, S.M.; Wilson, W.; Ito, K.; Van Donkelaar, C.C. A numerical model to study mechanically induced initiation and progression of damage in articular cartilage. Osteoarthr. Cartil. 2014, 22, 95-103. [CrossRef] [PubMed]

28. Stender, M.E.; Carpenter, R.D.; Regueiro, R.A.; Ferguson, V.L. An evolutionary model of osteoarthritis including articular cartilage damage, and bone remodeling in a computational study. J. Biomech. 2016, 49, 3502-3508. [CrossRef]

29. Párraga Quiroga, J.M.; Wilson, W.; Ito, K.; van Donkelaar, C.C. The effect of loading rate on the development of early damage in articular cartilage. Biomech. Model. Mechanobiol. 2017, 16, 263-273. [CrossRef] [PubMed]

30. Cooper, R.J.; Wilcox, R.K.; Jones, A.C. Finite element models of the tibiofemoral joint: A review of validation approaches and modelling challenges. Med. Eng. Phys. 2019, 74, 1-12. [CrossRef] [PubMed]

31. Chandrupatla, T.R.; Belegundu, A.D. Introduction to Finite Elements in Engineering, 3rd ed.; Prentice Hall: Hoboken, NJ, USA, 2002; ISBN 0130615919.

32. Bolcos, P.O.; Mononen, M.E.; Mohammadi, A.; Ebrahimi, M.; Tanaka, M.S.; Samaan, M.A.; Souza, R.B.; Li, X.; Suomalainen, J.S.; Jurvelin, J.S.; et al. Comparison between kinetic and kinetic-kinematic driven knee joint finite element models. Sci. Rep. 2018, 8, 1-11. [CrossRef] [PubMed]

33. Rodriguez-Vila, B.; Sánchez-González, P.; Oropesa, I.; Gomez, E.J.; Pierce, D.M. Automated hexahedral meshing of knee cartilage structures-Application to data from the osteoarthritis initiative. Comput. Methods Biomech. Biomed. Engin. 2017, 20, 1543-1553. [CrossRef] [PubMed]

34. Roberts, G.L.; Pallister, I. Finite element analysis in trauma \& orthopaedics-An introduction to clinically relevant simulation \& its limitations. Orthop. Trauma 2012, 26, 410-416. [CrossRef]

35. Henak, C.R.; Anderson, A.E.; Weiss, J.A. Subject-specific analysis of joint contact mechanics: Application to the study of osteoarthritis and surgical planning. J. Biomech. Eng. 2013, 135, 1-26. [CrossRef] [PubMed]

36. Wismans, J.; Veldpaus, F.; Jannsen, J. A three-dimensional mathematical model of the knee-joint. J. Biomech. 1980, 13, 677-685. [CrossRef]

37. Andriacchi, T.P.; Mikosz, R.P.; Hampton, S.J.; Galante, J.O. Model studies of the stiffness characteristics of the human knee joint. J. Biomech. 1983, 16, 23-29. [CrossRef]

38. Bendjaballah, M.Z.; Shirazi-Adl, A.; Zukor, D.J. Biomechanics of the human knee joint in compression: Reconstruction, mesh generation and finite element analysis. Knee 1995, 2, 69-79. [CrossRef]

39. Mukherjee, S.; Nazemi, M.; Jonkers, I.; Geris, L. Use of Computational Modeling to Study Joint Degeneration: A Review. Front. Bioeng. Biotechnol. 2020, 8, 1-20. [CrossRef]

40. Yang, N.H.; Canavan, P.K.; Nayeb-Hashemi, H.; Najafi, B.; Vaziri, A. Protocol for constructing subject-specific biomechanical models of knee joint. Comput. Methods Biomech. Biomed. Engin. 2010, 13, 589-603. [CrossRef] [PubMed]

41. Hayashi, D.; Roemer, F.W.; Guermazi, A. Imaging for osteoarthritis. Ann. Phys. Rehabil. Med. 2016, 59, 161-169. [CrossRef]

42. Boswell, M.A.; Uhlrich, S.D.; Kidziński, T.K.; Kolesar, J.A.; Gold, G.E.; Beaupre, G.S.; Delp, S.L. A neural network to predict the knee adduction moment in patients with osteoarthritis using anatomical landmarks obtainable from 2D video analysis. Osteoarthr. Cartil. 2021, 29, 346-356. [CrossRef] [PubMed]

43. Neubert, A.; Wilson, K.J.; Engstrom, C.; Surowiec, R.K.; Paproki, A.; Johnson, N.; Crozier, S.; Fripp, J.; Ho, C.P. Comparison of 3D bone models of the knee joint derived from CT and 3T MR imaging. Eur. J. Radiol. 2017, 93, 178-184. [CrossRef] [PubMed]

44. Ambellan, F.; Tack, A.; Ehlke, M.; Zachow, S. Automated Segmentation of Knee Bone and Cartilage combining Statistical Shape Knowledge and Convolutional Neural Networks: Data from the Osteoarthritis Initiative. Med. Image Anal. 2018, 52, 109-118. [CrossRef] [PubMed]

45. Baldwin, M.A.; Langenderfer, J.E.; Rullkoetter, P.J.; Laz, P.J. Development of subject-specific and statistical shape models of the knee using an efficient segmentation and mesh-morphing approach. Comput. Methods Programs Biomed. 2010, 97, 232-240. [CrossRef]

46. Tack, A.; Mukhopadhyay, A.; Zachow, S. Knee menisci segmentation using convolutional neural networks: Data from the Osteoarthritis Initiative. Osteoarthr. Cartil. 2018, 26, 680-688. [CrossRef] [PubMed]

47. Anderson, D.D.; Segal, N.A.; Kern, A.M.; Nevitt, M.C.; Torner, J.C.; Lynch, J.A. Reliability of Semiautomated Computational Methods for Estimating Tibiofemoral Contact Stress in the Multicenter Osteoarthritis Study. Comput. Math. Methods Med. 2012, 2012, 8. [CrossRef] [PubMed]

48. Das Neves Borges, P.; Forte, A.E.; Vincent, T.L.; Dini, D.; Marenzana, M. Rapid, automated imaging of mouse articular cartilage by microCT for early detection of osteoarthritis and finite element modelling of joint mechanics. Osteoarthr. Cartil. 2014, 22, 1419-1428. [CrossRef] [PubMed]

49. Rao, C.; Fitzpatrick, C.K.; Rullkoetter, P.J.; Maletsky, L.P.; Kim, R.H.; Laz, P.J. A statistical finite element model of the knee accounting for shape and alignment variability. Med. Eng. Phys. 2013, 35, 1450-1456. [CrossRef] [PubMed]

50. Mohammadi, A.; Myller, K.A.H.; Tanska, P.; Hirvasniemi, J.; Saarakkala, S.; Töyräs, J.; Korhonen, R.K.; Mononen, M.E. Rapid CT-based Estimation of Articular Cartilage Biomechanics in the Knee Joint Without Cartilage Segmentation. Ann. Biomed. Eng. 2020, 48, 2965-2975. [CrossRef]

51. Ebrahimkhani, S.; Jaward, M.H.; Cicuttini, F.M.; Dharmaratne, A.; Wang, Y.; de Herrera, A.G.S. A review on segmentation of knee articular cartilage: From conventional methods towards deep learning. Artif. Intell. Med. 2020, 106, 101851. [CrossRef] 
52. Paproki, A.; Engstrom, C.; Chandra, S.S.; Neubert, A.; Fripp, J.; Crozier, S. Automated segmentation and analysis of normal and osteoarthritic knee menisci from magnetic resonance images-Data from the Osteoarthritis Initiative. Osteoarthr. Cartil. 2014, 22, 1259-1270. [CrossRef] [PubMed]

53. Viceconti, M.; Bellingeri, L.; Cristofolini, L.; Toni, A. A comparative study on different methods of automatic mesh generation of human femurs. Med. Eng. Phys. 1998, 20, 1-10. [CrossRef]

54. Ramos, A.; Simões, J.A. Tetrahedral versus hexahedral finite elements in numerical modelling of the proximal femur. Med. Eng. Phys. 2006, 28, 916-924. [CrossRef]

55. McErlain, D.D.; Milner, J.S.; Ivanov, T.G.; Jencikova-Celerin, L.; Pollmann, S.I.; Holdsworth, D.W. Subchondral cysts create increased intra-osseous stress in early knee OA: A finite element analysis using simulated lesions. Bone 2011, 48, 639-646. [CrossRef] [PubMed]

56. Tadepalli, S.C.; Erdemir, A.; Cavanagh, P.R. Comparison of hexahedral and tetrahedral elements in finite element analysis of the foot and footwear. J. Biomech. 2011, 44, 2337-2343. [CrossRef] [PubMed]

57. Maas, S.A.; Ellis, B.J.; Rawlins, D.S.; Weiss, J.A. Finite element simulation of articular contact mechanics with quadratic tetrahedral elements. J. Biomech. 2016, 49, 659-667. [CrossRef] [PubMed]

58. Erdemir, A. Open Knee: Open Source Modeling \& Simulation to Enable Scientific Discovery and Clinical Care in Knee Biomechanics. J. Knee Surg. 2016, 29, 107-116. [CrossRef]

59. Wilson, W.; Van Donkelaar, C.C.; Van Rietbergen, B.; Ito, K.; Huiskes, R. Stresses in the local collagen network of articular cartilage: A poroviscoelastic fibril-reinforced finite element study. J. Biomech. 2004, 37, 357-366. [CrossRef]

60. Klets, O.; Mononen, M.E.; Tanska, P.; Nieminen, M.T.; Korhonen, R.K.; Saarakkala, S. Comparison of different material models of articular cartilage in 3D computational modeling of the knee: Data from the Osteoarthritis Initiative (OAI). J. Biomech. 2016, 49, 3891-3900. [CrossRef] [PubMed]

61. García, J.J.; Cortés, D.H. A biphasic viscohyperelastic fibril-reinforced model for articular cartilage: Formulation and comparison with experimental data. J. Biomech. 2007, 40, 1737-1744. [CrossRef]

62. Ateshian, G.A.; Rajan, V.; Chahine, N.O.; Canal, C.E.; Hung, C.T. Modeling the Matrix of Articular Cartilage Using a Continuous Fiber Angular Distribution Predicts Many Observed Phenomena. J. Biomech. Eng. 2009, 131, 612-615. [CrossRef]

63. Peters, A.E.; Akhtar, R.; Comerford, E.J.; Bates, K.T. Tissue material properties and computational modelling of the human tibiofemoral joint: A critical review. PeerJ 2018, 6, 1-48. [CrossRef]

64. Shirazi, R.; Shirazi-Adl, A.; Hurtig, M. Role of cartilage collagen fibrils networks in knee joint biomechanics under compression. J. Biomech. 2008, 41, 3340-3348. [CrossRef] [PubMed]

65. Keenan, K.E.; Pal, S.; Lindsey, D.P.; Besier, T.F.; Beaupre, G.S. A viscoelastic constitutive model can accurately represent entire creep indentation tests of human patella cartilage. J. Appl. Biomech. 2013, 29, 292-302. [CrossRef]

66. Thomas, G.C.; Asanbaeva, A.; Vena, P.; Sah, R.L.; Klisch, S.M. A nonlinear constituent based viscoelastic model for articular cartilage and analysis of tissue remodeling due to altered glycosaminoglycan-collagen interactions. J. Biomech. Eng. 2009, 131, 1-11. [CrossRef] [PubMed]

67. Soltz, M.A.; Ateshian, G.A. A conewise linear elasticity mixture model for the analysis of tension-compression nonlinearity in articular cartilage. J. Biomech. Eng. 2000, 122, 576-586. [CrossRef]

68. Soltz, M.A.; Ateshian, G.A. Experimental verification and theoretical prediction of cartilage interstitial fluid pressurization at an impermeable contact interface in confined compression. J. Biomech. 1998, 31, 927-934. [CrossRef]

69. Biot, M.A. General theory of three-dimensional consolidation. J. Appl. Phys. 1941, 12, 155-164. [CrossRef]

70. Mow, V.C.; Kuei, S.C.; Lai, W.M.; Armstrong, C.G. Biphasic creep and stress relaxation of articular cartilage in compression: Theory and experiments. J. Biomech. Eng. 1980, 102, 73-84. [CrossRef] [PubMed]

71. Holmes, M.H.; Mow, V.C. The nonlinear characteristics of soft gels and hydrated connective tissues in ultrafiltration. J. Biomech. 1990, 23, 1145-1156. [CrossRef]

72. Lai, W.M.; Mow, V.C. Drag-induced compression of articular cartilage during a permeation experiment. Biorheology 1980, 17, 111-123. [CrossRef] [PubMed]

73. Simon, B.R. Multiphase poroelastic finite element models for soft tissue structures. Appl. Mech. Rev. 1992, 45, 191-218. [CrossRef]

74. DiSilvestro, M.R.; Suh, J.K.F. A cross-validation of the biphasic poroviscoelastic model of articular cartilage in unconfined compression, indentation, and confined compression. J. Biomech. 2001, 34, 519-525. [CrossRef]

75. García, J.J.; Cortés, D.H. A nonlinear biphasic viscohyperelastic model for articular cartilage. J. Biomech. 2006, 39, 2991-2998 [CrossRef] [PubMed]

76. Suh, J.K.; Bai, S. Finite element formulation of biphasic poroviscoelastic model for articular cartilage. J. Biomech. Eng. 1998, 120, 195-201. [CrossRef]

77. Mak, A.F. The apparent viscoelastic behavior of articular cartilage-the contributions from the intrinsic matrix viscoelasticity and interstitial fluid flows. J. Biomech. Eng. 1986, 108, 123-130. [CrossRef] [PubMed]

78. Pierce, D.M.; Unterberger, M.J.; Trobin, W.; Ricken, T.; Holzapfel, G.A. A microstructurally based continuum model of cartilage viscoelasticity and permeability incorporating measured statistical fiber orientations. Biomech. Model. Mechanobiol. 2016, 15, 229-244. [CrossRef] 
79. Pierce, D.M.; Ricken, T.; Holzapfel, G.A. A hyperelastic biphasic fibre-reinforced model of articular cartilage considering distributed collagen fibre orientations: Continuum basis, computational aspects and applications. Comput. Methods Biomech. Biomed. Engin. 2013, 16, 1344-1361. [CrossRef] [PubMed]

80. Julkunen, P.; Kiviranta, P.; Wilson, W.; Jurvelin, J.S.; Korhonen, R.K. Characterization of articular cartilage by combining microscopic analysis with a fibril-reinforced finite-element model. J. Biomech. 2007, 40, 1862-1870. [CrossRef] [PubMed]

81. Wilson, W.; Van Donkelaar, C.C.; Huyghe, J.M. A comparison between mechano-electrochemical and biphasic swelling theories for soft hydrated tissues. J. Biomech. Eng. 2005, 127, 158-165. [CrossRef] [PubMed]

82. Wilson, W.; Van Donkelaar, C.C.; Van Rietbergen, B.; Huiskes, R. A fibril-reinforced poroviscoelastic swelling model for articular cartilage. J. Biomech. 2005, 38, 1195-1204. [CrossRef] [PubMed]

83. Huyghe, J.M.; Jannsen, J. Quadriphasic mechanics of swelling incompressible porous media. Int. J. Eng. Sci. 1997, 35, 793-802. [CrossRef]

84. Lai, W.M.; Hou, J.S.; Mow, V.C. A triphasic theory for the swelling and deformation behaviors of articular cartilage. J. Biomech Eng. 1991, 113, 245-258. [CrossRef]

85. Linka, K.; Schäfer, A.; Hillgärtner, M.; Itskov, M.; Knobe, M.; Kuhl, C.; Hitpass, L.; Truhn, D.; Thuering, J.; Nebelung, S. Towards Patient-Specific Computational Modelling of Articular Cartilage on the Basis of Advanced Multiparametric MRI Techniques. Sci. Rep. 2019, 9, 1-13. [CrossRef]

86. Räsänen, L.P.; Tanska, P.; Mononen, M.E.; Lammentausta, E.; Zbýň, Š.; Venäläinen, M.S.; Szomolanyi, P.; van Donkelaar, C.C.; Jurvelin, J.S.; Trattnig, S.; et al. Spatial variation of fixed charge density in knee joint cartilage from sodium MRI-Implication on knee joint mechanics under static loading. J. Biomech. 2016, 49, 3387-3396. [CrossRef] [PubMed]

87. Räsänen, L.P.; Tanska, P.; Zbýň, Š.; van Donkelaar, C.C.; Trattnig, S.; Nieminen, M.T.; Korhonen, R.K. The effect of fixed charge density and cartilage swelling on mechanics of knee joint cartilage during simulated gait. J. Biomech. 2017, 61, 34-44. [CrossRef]

88. Park, J.Y.; Kim, J.K.; Cheon, J.E.; Lee, M.C.; Han, H.S. Meniscus Stiffness Measured with Shear Wave Elastography is Correlated with Meniscus Degeneration. Ultrasound Med. Biol. 2020, 46, 297-304. [CrossRef]

89. Adam, C.; Eckstein, F.; Milz, S.; Schulte, E.; Becker, C.; Putz, R. The distribution of cartilage thickness in the knee-joints of old-aged individuals measurement by A-mode ultrasound. Clin. Biomech. 1998, 13, 1-10. [CrossRef]

90. Liukkonen, J.; Lehenkari, P.; Hirvasniemi, J.; Joukainen, A.; Virén, T.; Saarakkala, S.; Nieminen, M.T.; Jurvelin, J.S.; Töyräs, J. Ultrasound Arthroscopy of Human Knee Cartilage and Subchondral Bone in vivo. Ultrasound Med. Biol. 2014, 40, 2039-2047. [CrossRef] [PubMed]

91. Schmitz, R.J.; Wang, H.M.; Polprasert, D.R.; Kraft, R.A.; Pietrosimone, B.G. Evaluation of knee cartilage thickness: A comparison between ultrasound and magnetic resonance imaging methods. Knee 2017, 24, 217-223. [CrossRef]

92. Hatami-Marbini, H.; Maulik, R. A Biphasic Transversely Isotropic Poroviscoelastic Model for the Unconfined Compression of Hydrated Soft Tissue. J. Biomech. Eng. 2016, 138, 1-6. [CrossRef] [PubMed]

93. Cohen, B.; Lai, W.M.; Mow, V.C. A transversely isotropic biphasic model for unconfined compression of growth plate and chondroepiphysis. J. Biomech. Eng. 1998, 120, 491-496. [CrossRef] [PubMed]

94. Garcia, J.J.; Altiero, N.J.; Haut, R.C. An approach for the stress analysis of transversely isotropic biphasic cartilage under impact load. J. Biomech. Eng. 1998, 120, 608-613. [CrossRef] [PubMed]

95. Bolcos, P.O.; Mononen, M.E.; Tanaka, M.S.; Yang, M.; Suomalainen, J.-S.; Nissi, M.J.; Töyräs, J.; Ma, B.; Li, X.; Korhonen, R.K. Identification of locations susceptible to osteoarthritis in patients with anterior cruciate ligament reconstruction: Combining knee joint computational modelling with follow-up T1 $\varrho$ and T2 imaging. Clin. Biomech. 2020, 79, 104844. [CrossRef] [PubMed]

96. Vaziri, A.; Nayeb-Hashemi, H.; Singh, A.; Tafti, B.A. Influence of meniscectomy and meniscus replacement on the stress distribution in human knee joint. Ann. Biomed. Eng. 2008, 36, 1335-1344. [CrossRef]

97. Danso, E.K.; Honkanen, J.T.J.; Saarakkala, S.; Korhonen, R.K. Comparison of nonlinear mechanical properties of bovine articular cartilage and meniscus. J. Biomech. 2014, 47, 200-206. [CrossRef] [PubMed]

98. Zielinska, B.; Haut Donahue, T.L. 3D finite element model of meniscectomy: Changes in joint contact behavior. J. Biomech. Eng. 2006, 128, 115-123. [CrossRef] [PubMed]

99. Párraga-Quiroga, J.M.; Emans, P.; Wilson, W.; Ito, K.; Donkelaar, C.C. Van Should a native depth-dependent distribution of human meniscus constitutive components be considered in FEA-models of the knee joint? J. Mech. Behav. Biomed. Mater. 2014, 38, 242-250. [CrossRef] [PubMed]

100. Guess, T.M.; Razu, S.; Jahandar, H.; Stylianou, A. Predicted loading on the menisci during gait: The effect of horn laxity. J. Biomech. 2015, 48, 1490-1498. [CrossRef]

101. Guess, T.M.; Thiagarajan, G.; Kia, M.; Mishra, M. A subject specific multibody model of the knee with menisci. Med. Eng. Phys. 2010, 32, 505-515. [CrossRef] [PubMed]

102. Peña, E.; Peña, J.A.; Doblaré, M. On modelling nonlinear viscoelastic effects in ligaments. J. Biomech. 2008, 41, $2659-2666$. [CrossRef]

103. Peña, E.; Calvo, B.; Martínez, M.A.; Doblaré, M. An anisotropic visco-hyperelastic model for ligaments at finite strains. Formulation and computational aspects. Int. J. Solids Struct. 2007, 44, 760-778. [CrossRef]

104. Freutel, M.; Schmidt, H.; Dürselen, L.; Ignatius, A.; Galbusera, F. Finite element modeling of soft tissues: Material models, tissue interaction and challenges. Clin. Biomech. 2014, 29, 363-372. [CrossRef] [PubMed] 
105. Peña, E.; Calvo, B.; Martínez, M.A.; Doblaré, M. A three-dimensional finite element analysis of the combined behavior of ligaments and menisci in the healthy human knee joint. J. Biomech. 2006, 39, 1686-1701. [CrossRef] [PubMed]

106. Orozco, G.A.; Tanska, P.; Mononen, M.E.; Halonen, K.S.; Korhonen, R.K. The effect of constitutive representations and structural constituents of ligaments on knee joint mechanics. Sci. Rep. 2018, 8, 1-15. [CrossRef]

107. Venäläinen, M.S.; Mononen, M.E.; Väänänen, S.P.; Jurvelin, J.S.; Töyräs, J.; Virén, T.; Korhonen, R.K. Effect of bone inhomogeneity on tibiofemoral contact mechanics during physiological loading. J. Biomech. 2016, 49, 1111-1120. [CrossRef] [PubMed]

108. Stender, M.E.; Regueiro, R.A.; Ferguson, V.L. A poroelastic finite element model of the bone-cartilage unit to determine the effects of changes in permeability with osteoarthritis. Comput. Methods Biomech. Biomed. Engin. 2017, 20, 319-331. [CrossRef]

109. Donahue, T.L.H.; Hull, M.L.; Rashid, M.M.; Jacobs, C.R. A finite element model of the human knee joint for the study of tibio-femoral contact. J. Biomech. Eng. 2002, 124, 273-280. [CrossRef] [PubMed]

110. Anwar, A.; Hu, Z.; Zhang, Y.; Gao, Y.; Tian, C.; Wang, X. Multiple Subchondral Bone Cysts Cause Deterioration of Articular Cartilage in Medial OA of Knee: A 3D Simulation Study. Front. Bioeng. Biotechnol. 2020, 8, 1-13. [CrossRef] [PubMed]

111. Ali, A.A.; Shalhoub, S.S.; Cyr, A.J.; Fitzpatrick, C.K.; Maletsky, L.P.; Rullkoetter, P.J.; Shelburne, K.B. Validation of predicted patellofemoral mechanics in a finite element model of the healthy and cruciate-deficient knee. J. Biomech. 2016, 49, 302-309. [CrossRef]

112. Richards, R.E.; Andersen, M.S.; Harlaar, J.; Noort, J.C. Van Den Relationship between knee joint contact forces and external knee joint moments in patients with medial knee osteoarthritis: Effects of gait modi fi cations. Osteoarthr. Cartil. 2018, 26, 1203-1214. [CrossRef] [PubMed]

113. Marouane, H.; Shirazi-Adl, A.; Adouni, M. Alterations in knee contact forces and centers in stance phase of gait: A detailed lower extremity musculoskeletal model. J. Biomech. 2016, 49, 185-192. [CrossRef] [PubMed]

114. Adouni, M.; Shirazi-Adl, A. Evaluation of knee joint muscle forces and tissue stresses-strains during gait in severe OA versus normal subjects. J. Orthop. Res. 2014, 32, 69-78. [CrossRef]

115. Besier, T.F.; Gold, G.E.; Delp, S.L.; Fredericson, M.; Beaupré, G.S. The influence of femoral internal and external rotation on cartilage stresses within the patellofemoral joint. J. Orthop. Res. 2008, 26, 1627-1635. [CrossRef] [PubMed]

116. Delp, S.L.; Anderson, F.C.; Arnold, A.S.; Loan, P.; Habib, A.; John, C.T.; Guendelman, E.; Thelen, D.G. OpenSim: Open-source software to create and analyze dynamic simulations of movement. IEEE Trans. Biomed. Eng. 2007, 54, 1940-1950. [CrossRef] [PubMed]

117. Burton, W.S.; Myers, C.A.; Rullkoetter, P.J. Machine learning for rapid estimation of lower extremity muscle and joint loading during activities of daily living. J. Biomech. 2021, 123, 110439. [CrossRef] [PubMed]

118. Halilaj, E.; Rajagopal, A.; Fiterau, M.; Hicks, J.L.; Hastie, T.J.; Delp, S.L. Machine learning in human movement biomechanics: Best practices, common pitfalls, and new opportunities. J. Biomech. 2018, 81, 1-11. [CrossRef] [PubMed]

119. Ardestani, M.M.; Chen, Z.; Wang, L.; Lian, Q.; Liu, Y.; He, J.; Li, D.; Jin, Z. A neural network approach for determining gait modifications to reduce the contact force in knee joint implant. Med. Eng. Phys. 2014, 36, 1253-1265. [CrossRef]

120. Ardestani, M.M.; Chen, Z.; Wang, L.; Lian, Q.; Liu, Y.; He, J.; Li, D.; Jin, Z. Feed forward artificial neural network to predict contact force at medial knee joint: Application to gait modification. Neurocomputing 2014, 139, 114-129. [CrossRef]

121. Kokkotis, C.; Moustakidis, S.; Papageorgiou, E.; Giakas, G.; Tsaopoulos, D.E. Machine learning in knee osteoarthritis: A review. Osteoarthr. Cartil. Open 2020, 2, 100069. [CrossRef]

122. Mononen, M.E.; Tanska, P.; Isaksson, H.; Korhonen, R.K. A novel method to simulate the progression of collagen degeneration of cartilage in the knee: Data from the osteoarthritis initiative. Sci. Rep. 2016, 6, 1-14. [CrossRef]

123. De Brabandere, A.; Emmerzaal, J.; Timmermans, A.; Jonkers, I.; Vanwanseele, B.; Davis, J. A Machine Learning Approach to Estimate Hip and Knee Joint Loading Using a Mobile Phone-Embedded IMU. Front. Bioeng. Biotechnol. 2020, 8, 1-11. [CrossRef] [PubMed]

124. Fitzpatrick, C.K.; Rullkoetter, P.J. Estimating total knee replacement joint load ratios from kinematics. J. Biomech. 2014, 47, 3003-3011. [CrossRef] [PubMed]

125. Hume, D.R.; Navacchia, A.; Ali, A.A.; Shelburne, K.B. The interaction of muscle moment arm, knee laxity, and torque in a multi-scale musculoskeletal model of the lower limb. J. Biomech. 2018, 76, 173-180. [CrossRef]

126. Rooks, N.B.; Schneider, M.T.Y.; Erdemir, A.; Halloran, J.P.; Laz, P.J.; Shelburne, K.B.; Hume, D.R.; Imhauser, C.W.; Zaylor, W.; Elmasry, S.; et al. Deciphering the "art" in Modeling and Simulation of the Knee Joint: Variations in Model Development. J. Biomech. Eng. 2021, 143, 1-12. [CrossRef] [PubMed]

127. Navacchia, A.; Hume, D.R.; Rullkoetter, P.J.; Shelburne, K.B. A computationally efficient strategy to estimate muscle forces in a finite element musculoskeletal model of the lower limb. J. Biomech. 2019, 84, 94-102. [CrossRef]

128. Shelburne, K.B.; Torry, M.R.; Pandy, M.G. Muscle, ligament, and joint-contact forces at the knee during walking. Med. Sci. Sports Exerc. 2005, 37, 1948-1956. [CrossRef]

129. Tanska, P.; Mononen, M.E.; Korhonen, R.K. A multi-scale finite element model for investigation of chondrocyte mechanics in normal and medial meniscectomy human knee joint during walking. J. Biomech. 2015, 48, 1397-1406. [CrossRef] [PubMed]

130. Esrafilian, A.; Stenroth, L.; Mononen, M.E.; Tanska, P.; Avela, J.; Korhonen, R.K. EMG-Assisted Muscle Force Driven Finite Element Model of the Knee Joint with Fibril-Reinforced Poroelastic Cartilages and Menisci. Sci. Rep. 2020, 10, 1-16. [CrossRef] 
131. Halloran, J.P.; Sibole, S.; Van Donkelaar, C.C.; Van Turnhout, M.C.; Oomens, C.W.J.; Weiss, J.A.; Guilak, F.; Erdemir, A. Multiscale mechanics of articular cartilage: Potentials and challenges of coupling musculoskeletal, joint, and microscale computational models. Ann. Biomed. Eng. 2012, 40, 2456-2474. [CrossRef] [PubMed]

132. Guilak, F; Mow, V.C. The mechanical environment of the chondrocyte: A biphasic finite element model of cell-matrix interactions in articular cartilage. J. Biomech. 2000, 33, 1663-1673. [CrossRef]

133. Fitzpatrick, C.K.; Baldwin, M.A.; Rullkoetter, P.J. Computationally efficient finite element evaluation of natural patellofemoral mechanics. J. Biomech. Eng. 2010, 132, 1-8. [CrossRef] [PubMed]

134. Maas, S.A.; Ateshian, G.A.; Weiss, J.A. FEBio: History and Advances. Annu. Rev. Biomed. Eng. 2017, 19, 279-299. [CrossRef]

135. Maas, S.A.; Ellis, B.J.; Ateshian, G.A.; Weiss, J.A. FEBio: Finite elements for biomechanics. J. Biomech. Eng. 2012, 134, 1-10. [CrossRef] [PubMed]

136. Erdemir, A.; Guess, T.M.; Halloran, J.; Tadepalli, S.C.; Morrison, T.M. Considerations for reporting finite element analysis studies in biomechanics. J. Biomech. 2012, 45, 625-633. [CrossRef]

137. Yao, J.; Salo, A.D.; Lee, J.; Lerner, A.L. Sensitivity of tibio-menisco-femoral joint contact behavior to variations in knee kinematics. J. Biomech. 2008, 41, 390-398. [CrossRef] [PubMed]

138. Haut Donahue, T.L.; Hull, M.L.; Rashid, M.M.; Jacobs, C.R. How the stiffness of meniscal attachments and meniscal material properties affect tibio-femoral contact pressure computed using a validated finite element model of the human knee joint. $J$. Biomech. 2003, 36, 19-34. [CrossRef]

139. Peña, E.; Calvo, B.; Martínez, M.A.; Doblaré, M. Effect of the size and location of osteochondral defects in degenerative arthritis. A finite element simulation. Comput. Biol. Med. 2007, 37, 376-387. [CrossRef]

140. Kempson, G.E. Relationship between the tensile properties of articular cartilage from the human knee and age. Ann. Rheum. Dis. 1982, 41, 508-511. [CrossRef]

141. Calce, S.E.; Kurki, H.K.; Weston, D.A.; Gould, L. The relationship of age, activity, and body size on osteoarthritis in weight-bearing skeletal regions. Int. J. Paleopathol. 2018, 22, 45-53. [CrossRef]

142. Whittaker, J.L.; Woodhouse, L.J.; Nettel-Aguirre, A.; Emery, C.A. Outcomes associated with early post-traumatic osteoarthritis and other negative health consequences 3-10 years following knee joint injury in youth sport. Osteoarthr. Cartil. 2015, 23, 1122-1129. [CrossRef]

143. Korhonen, R.K.; Laasanen, M.S.; Töyräs, J.; Lappalainen, R.; Helminen, H.J.; Jurvelin, J.S. Fibril reinforced poroelastic model predicts specifically mechanical behavior of normal, proteoglycan depleted and collagen degraded articular cartilage. J. Biomech. 2003, 36, 1373-1379. [CrossRef]

144. DiSilvestro, M.R.; Francis Suh, J.K. Biphasic poroviscoelastic characteristics of proteoglycan-depleted articular cartilage: Simulation of degeneration. Ann. Biomed. Eng. 2002, 30, 792-800. [CrossRef] [PubMed]

145. Korhonen, R.K.; Laasanen, M.S.; Töyräs, J.; Rieppob, J.; Hirvonen, J.; Helminen, H.J.; Jurvelin, J.S. Comparison of the equilibrium response of articular cartilage in unconfined compression, confined compression and indentation. J. Biomech. 2002, 35, 903-909. [CrossRef]

146. Orozco, G.A.; Bolcos, P.; Mohammadi, A.; Tanaka, M.S.; Yang, M.; Link, T.M.; Ma, B.; Li, X.; Tanska, P.; Korhonen, R.K. Prediction of local fixed charge density loss in cartilage following ACL injury and reconstruction: A computational proof-of-concept study with MRI follow-up. J. Orthop. Res. 2021, 39, 1064-1081. [CrossRef]

147. Eskelinen, A.S.A.; Tanska, P.; Florea, C.; Orozco, G.A.; Julkunen, P.; Grodzinsky, A.J.; Korhonen, R.K. Mechanobiological model for simulation of injured cartilage degradation via proinflammatory cytokines and mechanical. PLoS Comput. Biol. 2020, 16, 1-25. [CrossRef] [PubMed]

148. Shim, V.B.; Hunter, P.J.; Pivonka, P.; Fernandez, J.W. A multiscale framework based on the Physiome markup languages for exploring the initiation of osteoarthritis at the bone-cartilage interface. IEEE Trans. Biomed. Eng. 2011, 58, 3532-3536. [CrossRef]

149. Andriacchi, T.P.; Briant, P.L.; Bevill, S.L.; Koo, S. Rotational Changes at the Knee after ACL Injury Cause Cartilage Thinning. Clin. Orthop. Relat. Res. 2006, 442, 39-44. [CrossRef]

150. Mononen, M.E.; Julkunen, P.; Töyräs, J.; Jurvelin, J.S.; Kiviranta, I.; Korhonen, R.K. Alterations in structure and properties of collagen network of osteoarthritic and repaired cartilage modify knee joint stresses. Biomech. Model. Mechanobiol. 2011, 10, 357-369. [CrossRef] [PubMed]

151. Mononen, M.E.; Mikkola, M.T.; Julkunen, P.; Ojala, R.; Nieminen, M.T.; Jurvelin, J.S.; Korhonen, R.K. Effect of superficial collagen patterns and fibrillation of femoral articular cartilage on knee joint mechanics-A 3D finite element analysis. J. Biomech. 2012, 45, 579-587. [CrossRef]

152. Liukkonen, M.K.; Mononen, M.E.; Klets, O.; Arokoski, J.P.; Saarakkala, S.; Korhonen, R.K. Simulation of subject-specific progression of knee osteoarthritis and comparison to experimental follow-up data: Data from the osteoarthritis initiative. Sci. Rep. 2017, 7, 1-14. [CrossRef]

153. Elahi, S.A.; Tanska, P.; Mukherjee, S.; Korhonen, R.K.; Geris, L.; Jonkers, I.; Famaey, N. Guide to mechanical characterization of articular cartilage and hydrogel constructs based on a systematic in silico parameter sensitivity analysis. J. Mech. Behav. Biomed. Mater. 2021, 124, 104795. [CrossRef] [PubMed]

154. LeRoux, M.A.; Setton, L.A. Experimental and biphasic FEM determinations of the material properties and hydraulic permeability of the meniscus in tension. J. Biomech. Eng. 2002, 124, 315-321. [CrossRef] 
155. Wang, H.; Koff, M.F.; Potter, H.G.; Warren, R.F.; Rodeo, S.A.; Maher, S.A. An MRI-compatible loading device to assess knee joint cartilage deformation: Effect of preloading and inter-test repeatability. J. Biomech. 2015, 48, 2934-2940. [CrossRef] [PubMed]

156. Mootanah, R.; Imhauser, C.W.; Reisse, F.; Carpanen, D.; Walker, R.W.; Koff, M.F.; Lenhoff, M.W.; Rozbruch, S.R.; Fragomen, A.T.; Dewan, Z.; et al. Development and validation of a computational model of the knee joint for the evaluation of surgical treatments for osteoarthritis. Comput. Methods Biomech. Biomed. Engin. 2014, 17, 1502-1517. [CrossRef]

157. Halonen, K.S.; Mononen, M.E.; Jurvelin, J.S.; To, J. Deformation of articular cartilage during static loading of a knee jointExperimental and finite element analysis. J. Biomech. 2014, 47, 2467-2474. [CrossRef] [PubMed]

158. Chan, D.D.; Cai, L.; Butz, K.D.; Trippel, S.B.; Nauman, E.A.; Neu, C.P. In vivo articular cartilage deformation: Noninvasive quantification of intratissue strain during joint contact in the human knee. Sci. Rep. 2016, 6, 1-14. [CrossRef] [PubMed]

159. Adams, J.G.; McAlindon, T.; Dimasi, M.; Carey, J.; Eustace, S. Contribution of meniscal extrusion and cartilage loss to joint space narrowing in osteoarthritis. Clin. Radiol. 1999, 54, 502-506. [CrossRef]

160. Gale, D.R.; Chaisson, C.E.; Totterman, S.M.S.; Schwartz, R.K.; Gale, M.E.; Felson, D. Meniscal subluxation: Association with osteoarthritis and joint space narrowing. Osteoarthr. Cartil. 1999, 7, 526-532. [CrossRef] [PubMed]

161. Besier, T.F.; Gold, G.E.; Beaupré, G.S.; Delp, S.L. A modeling framework to estimate patellofemoral joint cartilage stress in vivo. Med. Sci. Sports Exerc. 2005, 37, 1924-1930. [CrossRef]

162. Scarvell, J.M.; Sc, B.A.; Smith, P.N.; Refshauge, K.M.; Galloway, H.R. Magnetic Resonance Imaging Analysis of Kinematics in Osteoarthritic Knees. J. Arthroplasty 2007, 22, 383-393. [CrossRef]

163. Kawashima, K.; Tomita, T. In vivo three-dimensional motion analysis of osteoarthritic knees. Mod. Rheumatol. 2013, 23, 646-652. [CrossRef] [PubMed]

164. Farrokhi, S.; Keyak, J.H.; Powers, C.M. Individuals with patellofemoral pain exhibit greater patellofemoral joint stress: A finite element analysis study. Osteoarthr. Cartil. 2011, 19, 287-294. [CrossRef] [PubMed]

165. Liu, F.; Kozanek, M.; Hosseini, A.; Van de Velde, S.K.; Gill, T.J.; Rubash, H.E.; Li, G. In vivo tibiofemoral cartilage deformation during the stance phase of gait. J. Biomech. 2010, 43, 658-665. [CrossRef] [PubMed]

166. Li, J.S.; Tsai, T.Y.; Wang, S.; Li, P.; Kwon, Y.M.; Freiberg, A.; Rubash, H.E.; Li, G. Prediction of in Vivo Knee Joint Kinematics Using a Combined Dual Fluoroscopy Imaging and Statistical Shape Modeling Technique. J. Biomech. Eng. 2014, 136, 124503. [CrossRef] [PubMed]

167. Culvenor, A.G.; Wirth, W.; Boeth, H.; Duda, G.N.; Eckstein, F. Longitudinal changes in location-specific cartilage thickness and T2 relaxation-times after posterior cruciate ligament reconstruction for isolated and multiligament injury. Clin. Biomech. 2020, 79, 104935. [CrossRef]

168. Pritzker, K.P.H.; Gay, S.; Jimenez, S.A.; Ostergaard, K.; Pelletier, J.P.; Revell, K.; Salter, D.; van den Berg, W.B. Osteoarthritis cartilage histopathology: Grading and staging. Osteoarthr. Cartil. 2006, 14, 13-29. [CrossRef] [PubMed]

169. Waldstein, W.; Perino, G.; Gilbert, S.L.; Maher, S.A.; Windhager, R.; Boettner, F. OARSI osteoarthritis cartilage histopathology assessment system: A biomechanical evaluation in the human knee. J. Orthop. Res. 2016, 34, 135-140. [CrossRef] [PubMed]

170. Caravaggi, P.; Assirelli, E.; Ensini, A.; Ortolani, M.; Mariani, E.; Leardini, A.; Neri, S.; Belvedere, C. Biomechanical-Based Protocol for in vitro Study of Cartilage Response to Cyclic Loading: A Proof-of-Concept in Knee Osteoarthritis. Front. Bioeng. Biotechnol. 2021, 9, 1-13. [CrossRef] [PubMed]

171. Du, Y.; Almajalid, R.; Shan, J.; Zhang, M. A Novel Method to Predict Knee Osteoarthritis Progression on MRI Using Machine Learning Methods. IEEE Trans. Nanobiosci. 2018, 17, 228-236. [CrossRef]

172. Kellgren, J.H.; Lawrence, J.S. Radiological Assessment of Osteo-Arthrosis. Ann. Rheum. Dis. 1957, 16, 494-502. [CrossRef] [PubMed]

173. Peterfy, C.G.; Schneider, E.; Nevitt, M. The osteoarthritis initiative: Report on the design rationale for the magnetic resonance imaging protocol for the knee. Osteoarthr. Cartil. 2008, 16, 1433-1441. [CrossRef] [PubMed]

174. Prendergast, P.J. Finite element models in tissue mechanics and orthopaedic implant design. Clin. Biomech. 1997, 12, 343-366. [CrossRef]

175. Li, L.; Yang, L.; Zhang, K.; Zhu, L.; Wang, X.; Jiang, Q. Three-dimensional finite-element analysis of aggravating medial meniscus tears on knee osteoarthritis. J. Orthop. Transl. 2020, 20, 47-55. [CrossRef]

176. Zhang, K.; Li, L.; Yang, L.; Shi, J.; Zhu, L.; Liang, H.; Wang, X.; Yang, X.; Jiang, Q. Effect of degenerative and radial tears of the meniscus and resultant meniscectomy on the knee joint: A finite element analysis. J. Orthop. Transl. 2019, 18, 20-31. [CrossRef]

177. Ji, W.; Luo, C.; Zhan, S.; Zhan, Y.; Xie, X.; Zhang, B. Combined proximal tibial osteotomy for varus osteoarthritis of the knee: Biomechanical tests and finite-element analyses. Knee 2020, 27, 863-870. [CrossRef]

178. Liukkonen, M.K.; Mononen, M.E.; Vartiainen, P.; Kaukinen, P.; Bragge, T.; Suomalainen, J.-S.; Malo, M.K.H.; Venesmaa, S.; Käkelä, P.; Pihlajamäki, J.; et al. Evaluation of the Effect of Bariatric Surgery-Induced Weight Loss on Knee Gait and Cartilage Degeneration. J. Biomech. Eng. 2018, 140, 041008. [CrossRef] [PubMed]

179. Cheung, R.T.H.; Ho, K.K.W.; Au, I.P.H.; An, W.W.; Zhang, J.H.W.; Chan, Z.Y.S.; Deluzio, K.; Rainbow, M.J. Immediate and shortterm effects of gait retraining on the knee joint moments and symptoms in patients with early tibiofemoral joint osteoarthritis: A randomized controlled trial. Osteoarthr. Cartil. 2018, 26, 1479-1486. [CrossRef]

180. Pizzolato, C.; Reggiani, M.; Saxby, D.J.; Ceseracciu, E.; Modenese, L.; Lloyd, D.G. Biofeedback for Gait Retraining Based on Real-Time Estimation of Tibiofemoral Joint Contact Forces. IEEE Trans. Neural Syst. Rehabil. Eng. 2017, 25, 1612-1621. [CrossRef] [PubMed] 
181. Richards, R.; Van Den Noort, J.C.; Van Der Esch, M.; Booij, M.J.; Harlaar, J. Gait retraining using real-time feedback in patients with medial knee osteoarthritis: Feasibility and effects of a six-week gait training program. Knee 2018, 25, 814-824. [CrossRef] [PubMed]

182. Bowes, M.A.; Guillard, G.A.; Vincent, G.R.; Brett, A.D.; Brian, C.; Wolstenholme, H.; Conaghan, P.G. Precision, Reliability, and Responsiveness of a Novel Automated Quantification Tool for Cartilage Thickness: Data from the Osteoarthritis Initiative. J. Rheumatol. 2020, 47, 282-289. [CrossRef] [PubMed]

183. Litjens, G.; Kooi, T.; Bejnordi, B.E.; Setio, A.A.A.; Ciompi, F.; Ghafoorian, M.; van der Laak, J.A.W.M.; van Ginneken, B.; Sánchez, C.I. A survey on deep learning in medical image analysis. Med. Image Anal. 2017, 42, 60-88. [CrossRef]

184. Teng, H.; Pedoia, V.; Link, T.M.; Majumdar, S.; Souza, R.B. Local associations between knee cartilage T1 $\varrho$ and T2 relaxation times and patellofemoral joint stress during walking: A voxel-based relaxometry analysis. Knee 2018, 25, 406-416. [CrossRef] [PubMed]

185. Teng, H.; Calixto, N.E.; Macleod, T.D.; Nardo, L.; Link, T.M.; Majumdar, S.; Souza, R.B. Associations between patellofemoral joint cartilage $\mathrm{T} 1 \varrho$ and $\mathrm{T} 2$ and knee flexion moment and impulse during gait in individuals with and without patellofemoral joint osteoarthritis. Osteoarthr. Cartil. 2016, 24, 1554-1564. [CrossRef] [PubMed]

186. Tang, S.Y.; Souza, R.B.; Ries, M.; Hansma, P.K.; Alliston, T.; Li, X. Local Tissue Properties of Human Osteoarthritic Cartilage Correlate with Magnetic Resonance T 1 rho Relaxation Times. J. Orthop. Res. 2011, 29, 1312-1319. [CrossRef] [PubMed]

187. Chaudhari, A.S.; Kogan, F.; Pedoia, V.; Majumdar, S.; Gold, G.E.; Hargreaves, B.A. Rapid Knee MRI Acquisition and Analysis Techniques for Imaging Osteoarthritis. J. Magn. Reson. Imaging 2020, 52, 1321-1339. [CrossRef]

188. Zibetti, M.V.W.; Baboli, R.; Chang, G.; Otazo, R.; Regatte, R.R. Rapid Compositional Mapping of Knee Cartilage With Compressed Sensing MRI. J. Magn. Reson. Imaging 2018, 48, 1185-1198. [CrossRef]

189. Marques, J.; Genant, H.K.; Lillholm, M.; Dam, E.B. Diagnosis of Osteoarthritis and Prognosis of Tibial Cartilage Loss by Quantification of Tibia Trabecular Bone from MRI. Magn. Reson. Med. 2013, 575, 568-575. [CrossRef] [PubMed]

190. Ratzlaff, C.; Guermazi, A.; Collins, J.; Katz, J.N.; Losina, E.; Vanwyngaarden, C.; Russell, R.; Iranpour, T.; Duryea, J. A rapid, novel method of volumetric assessment of MRI-detected subchondral bone marrow lesions in knee osteoarthritis. Osteoarthr. Cartil. 2013, 21, 806-814. [CrossRef]

191. Hirvasniemi, J.; Niinimäki, J.; Thevenot, J.; Saarakkala, S. Bone Density and Texture from Minimally Post-Processed Knee Radiographs in Subjects with Knee Osteoarthritis. Ann. Biomed. Eng. 2019, 47, 1181-1190. [CrossRef] [PubMed]

192. Moerman, K.M.; Holt, C.A.; Evans, S.L.; Simms, C.K. Digital image correlation and finite element modelling as a method to determine mechanical properties of human soft tissue in vivo. J. Biomech. 2009, 42, 1150-1153. [CrossRef]

193. Wu, J.; Qian, Z.; Liang, W.; Liu, J.; Ren, L.; Ren, L. In vivo assessment of material properties of muscles and connective tissues around the knee joint based on shear wave elastography. J. Mech. Behav. Biomed. Mater. 2020, 109, 103829. [CrossRef] [PubMed]

194. Teng, H.; MacLeod, T.D.; Kumar, D.; Link, T.M.; Majumdar, S.; Souza, R.B. Individuals with isolated patellofemoral joint osteoarthritis exhibit higher mechanical loading at the knee during the second half of the stance phase. Clin. Biomech. 2015, 30, 383-390. [CrossRef]

195. Ho, K.; Blanchette, M.G.; Powers, C.M. The influence of heel height on patellofemoral joint kinetics during walking. Gait Posture 2012, 36, 271-275. [CrossRef] [PubMed]

196. Brechter, J.H.; Powers, C.M. Patellofemoral stress during walking in persons with and without patellofemoral pain. Med. Sci. Sport. Exerc. 2002, 34, 1582-1593. [CrossRef] [PubMed]

197. Van Eijden, T.M.G.J.; Kuowenhoven, E.; Verburg, J.; Weijs, W.A. A Mathematical Model of The Patellofemoral Joint. J. Biomech. 1986, 19, 219-229. [CrossRef]

198. Gustafson, J.A.; Elias, J.J.; Debski, R.E.; Farrokhi, S. Development and validation of a kinematically-driven discrete element model of the patellofemoral joint. J. Biomech. 2019, 88, 164-172. [CrossRef]

199. Li, M.; Venäläinen, M.S.; Chandra, S.S.; Patel, R.; Fripp, J.; Engstrom, C.; Korhonen, R.K.; Töyräs, J.; Crozier, S. Discrete element and finite element methods provide similar estimations for hip joint contact mechanics during walking gait. J. Biomech. 2021, 115, 110163. [CrossRef] [PubMed]

200. Thomas-Aitken, H.D.; Willey, M.C.; Goetz, J.E. Joint contact stresses calculated for acetabular dysplasia patients using discrete element analysis are significantly influenced by the applied gait pattern. J. Biomech. 2018, 79, 45-53. [CrossRef]

201. Chen, P.; Gao, L.; Shi, X.; Allen, K.; Yang, L. Fully automatic knee osteoarthritis severity grading using deep neural networks with a novel ordinal loss. Comput. Med. Imaging Graph. 2019, 75, 84-92. [CrossRef] [PubMed]

202. Kessler, D.A.; MacKay, J.W.; Crowe, V.A.; Henson, F.M.D.; Graves, M.J.; Gilbert, F.J.; Kaggie, J.D. The optimisation of deep neural networks for segmenting multiple knee joint tissues from MRIs. Comput. Med. Imaging Graph. 2020, 86, 101793. [CrossRef]

203. Tiulpin, A.; Thevenot, J.; Rahtu, E.; Lehenkari, P.; Saarakkala, S. Automatic knee osteoarthritis diagnosis from plain radiographs: A deep learning-based approach. Sci. Rep. 2018, 8, 1-10. [CrossRef] [PubMed] 